Revista de Estudios Histórico-Jurídicos

[Sección historia del derecho europeo]

XL (Valparaíso, Chile, 2018)

[pp. 183 - 212]

\title{
EL DELITO DE ADULTERIO EN TRES FUEROS DE LA FAMILIA DE LEÓN-BENAVENTE. UNA APROXIMACIÓN INTERDISCIPLINAR AL DERECHO MEDIEVAL ESPAÑOL*
}

[The Crime of Adultery in three fueros of the Family of León-Benavente. An Interdisciplinary Approach to Spanish Medieval Law]

\author{
Plácido Fernández-Viagas Escudero** \\ Universidad de Sevilla, España
}

\begin{abstract}
RESUMEN
Esta contribución de historia cultural del derecho puede ser considerada como un trabajo interdisciplinar, que estudia la legislación de la época bajo una lógica jurídica, pero que también utiliza aportaciones de sociólogos y antropólogos en diferentes puntos, particularmente en
\end{abstract} ABSTRACT
This paper of cultural history of law
can be considered as an interdisciplinary
work, that studies the legislation of the
time by using juridical logic, but also
the contributions of sociologists and
anthropologists in different points,
particularly in matters of dishonor and

RECIBIDO el 2 de septiembre de 2017 y ACEPTADO el 6 de abril de 2018

* Téngase presente que los fueros de la familia de León-Benavente y otras fuentes jurídicas empleadas en el presente trabajo son citadas bajo nombre abreviado y seguidas de un número referido a la ley en cuestión, siempre que se encuentren numeradas sus normas en la edición manejada. En cuanto a las fuentes no jurídicas, son citadas asimismo bajo nombre abreviado y seguidas de la abreviatura $p$. o $f$., que hace referencia a la página o folio referido. Las ediciones de todas las fuentes serán recogidas en forma desarrollada en el apartado quinto, titulado Fuentes empleadas. Las abreviaturas generadas para el presente trabajo son las siguientes: 12 Sabios = El libro de los doce sabios; CEM. = Cantigas de escarnio y maldecir; C.= Crónica; Co. = Concilio; Cod. $=$ Código; Cor. $=$ Cortes; Dig. $=$ Digesto; DRH. $=$ De Rebus Hispaniae; F. = Fuero; G. $=$ General; GCU. $=$ Gran Conquista de Ultramar; GE. = General Estoria; L. = Liber/libro; pr. $=$ proemio; PCG. $=$ Primera Crónica General; U. = Usatges; V. = Vidal.

${ }^{* *}$ Licenciado en Derecho y graduado en Historia por la Universidad de Sevilla y licenciado en Antropología Social y Cultural por la Universidad Nacional de Educación a Distancia. Doctorando en Historia Medieval por la Universidad de Sevilla. Departamento de Historia Medieval y Ciencias y Técnicas Historiográficas, Facultad de Geografía e Historia, c/ Doña María de Padilla, s/n, 41004, Sevilla (España). Correo electrónico: placidofve@gmail.com. 
materia de deshonra y separación ritual. $\mathrm{Su}$ objetivo es interpretar las normas que regulaban el delito de adulterio en los fueros de Parga, Llanes y Puebla de Sanabria bajo el entramado jurídico y simbólico del que formaban parte. En esta tarea, descubriremos las fuentes romanas de este delito en los dos primeros fueros y analizaremos la autoría de Alfonso X respecto de las normas estudiadas del fuero de Puebla de Sanabria.

\section{PaLABRAs CLAVE}

Adulterio - Llanes - Parga - Puebla de Sanabria - Siglo XIII - Alfonso X. ritual separation. Its goal is to interpret the norms that regulated the crime of adultery in the fueros of Parga, Llanes and Puebla de Sanabria in its legal and symbolic framework. In this work, we will discover the Roman sources of this crime in the first two fueros and we will analyze the authorship of Alfonso X in these norms of the fuero of Puebla de Sanabria.

\section{KEYWORDS}

Adultery - Llanes - Parga - Puebla de Sanabria - 13th century - Alfonso X.

\section{INTRODUCCIÓN}

Esta contribución constituye un estudio de historia cultural del derecho, que aborda la regulación del adulterio en los únicos fueros municipales conservados de la familia de fueros de León-Benavente que lo contemplaban con la intención de interpretar sus normas principalmente con una lógica jurídica, pero que además analiza las tramas de significación contenidas en la legislación desde una perspectiva más amplia, para lo cual empleamos herramientas interpretativas de otras ciencias sociales. En esta labor nos serviremos de una interpretación sociológica de las normas, bajo la inspiración de una técnica etnográfica, llamada descripción densa ${ }^{1}$, que nos sugiere trabajar con una amplia diversidad de fuentes con las que reconstruir las estructuras conceptuales del contexto jurídico y cultural de aquella época.

Al margen de este enfoque, y para un estudio en detalle respecto de algunas materias, nos servimos también de las aportaciones de diferentes disciplinas, que nos ofrecen categorías provechosas para nuestro análisis y nos proporcionan un cuerpo teórico para comprender las instituciones sociales y jurídicas evidenciadas en estas normas. De esta manera, en cuanto a la interpretación de la pena corporal prevista en las mismas, utilizamos un enfoque de raíz durkheimiana, con el que abordar las implicaciones simbólicas de la separación del delincuente del mundo profano y comprender la contaminación generada a causa del delito, desde la sociología de las religiones.

Respecto de los principales documentos que requieren nuestra atención, la familia de fueros de León-Benavente tuvo su origen en el año 1017 con la primera redacción del Fuero de León, y, a lo largo de los siglos XII, XIII y XIV se expandió por el territorio de las antiguos reinos de León y de Castilla ${ }^{2}$ como una de las

${ }^{1}$ Respecto de esta técnica etnográfica, cfr. GEeRTz, Clifford, La interpretación de las culturas (1973, Gedisa, reimp. Barcelona, 2003).

2 Véase su expansión en Barrero García, Ana María y Alonso Martín, María Luz, Tex- 
familias de fueros no extensos con mayor implantación territorial de la península, con dos focos de influencia bien delimitados, correspondientes al derecho leonés, así como al derecho benaventano. Su expansión sobre la península, así como la regulación de determinadas instituciones sociales abordadas también en los espejos de príncipes y en un gran número de fuentes de la época, nos permitirá interpretar determinadas leyes en su contexto cultural y extraer conclusiones más elaboradas para afrontar el estudio del período histórico.

En cuanto a la cuestión estrictamente penal, el delito de adulterio no se encontraba regulado ni en el derecho leonés, ni en el derecho benaventano conservado. En cambio, este delito sí lo hallamos en los fueros de Parga, de 1225, y de Llanes (de fecha incierta, pero probablemente de la misma década que el de $\operatorname{Parga}^{3}$ ), por derivación de lo previsto sobre la materia en una reelaboración del fuero de Benavente, presumiblemente en tiempos de Alfonso IX, que hoy no se conserva ${ }^{4}$. Al respecto, como desarrollaremos con detenimiento, podemos afirmar que la regulación sobre el adulterio de este fuero de Benavente y de los fueros de Parga y Llanes, recoge una influencia del derecho común, que supone su primera vía de penetración conocida en la regulación del delito de adulterio dentro del derecho municipal castellano o leonés, y que se conjugaba en estos fueros con un sustrato jurídico procedente del derecho peninsular previo. En consecuencia, junto con diferentes tareas, en el presente trabajo nos detendremos en analizar esta vía de penetración, pues ello nos arrojará luz no sólo en la comprensión de la regulación del delito de adulterio en esta familia de fueros, sino también en una cuestión fundamental, cual es la de la progresiva incorporación del derecho justinianeo en el derecho peninsular prealfonsís.

Por otra parte, analizaremos un fuero diferente de esta familia, el de Puebla de Sanabria, aprobado por el rey Alfonso IX en 1220 y confirmado por Alfonso X en 1263 introduciendo ciertas modificaciones. Entre estas modificaciones encontra-

tos de derecho local español en la Edad Media: catálogo de fueros y costums municipales (Madrid, CSIC, 1989), p. 548.

${ }^{3}$ Para el debate historiográfico sobre la cuestión, cfr. Calleja Puerta, Miguel (ed.), El fuero de Llanes, Edición crítica (Oviedo, Sueve, 2000), pp. 38-41.

${ }^{4}$ Cfr. García-Gallo de Diego, Alfonso, Los fueros de Benavente, en Anuario de Historia del Derecho Español, 41 (1971), pp. 1143 ss.

${ }^{5}$ Para una panorámica general de esta recepción previa a la labor jurídica de Alfonso X, cfr. Clavero, Bartolomé, Historia del Derecho: Derecho común (Salamanca, Universidad de Salamanca, 2008), GarCía GARCÍA, Antonio, Derecho común en España. Los juristas y su obra (Murcia, Universidad de Murcia, 1991) y Derecho común en Castilla durante el siglo XIII, en Glossae: European Journal of Legal History, 5-6 (1993-1994), pp. 45 ss. y Pérez MARTín, Antonio, El estudio de la recepción del derecho común en España, en SALVAdOR Coderch, Pablo y Cerdá Ruiz-Fues, Joaquím (coords.), I Seminario de historia del derecho y derecho privado: nuevas técnicas de investigación (Barcelona, Universitat Autónoma de Barcelona, 1985), pp. 241 ss. y Los fueros extensos y el derecho común, en Anales de Derecho, 15 (1997), pp. 75 ss. En todo caso, los estudios más precisos sobre la materia se centran en las influencias de derecho romano en la familia de fueros de Cuenca-Teruel, como se comprueba en GARCÍA SÁnCHEZ, Justo, Los derechos reales romanos en el fuero de Cuenca, en Glossae: European Journal of Legal History, 8 (1996), pp. 53 ss. y PÉREz MARTín, Antonio, El derecho común y el fuero de Cuenca, en Glossae: European Journal of Legal History, 8 (1996), pp. 77 ss. 
mos, asimismo, regulada la cuestión del adulterio, que también interpretaremos a la luz del entramado jurídico y cultural de la época, para extraer mayor información a los datos que se nos presentan. Por lo tanto, los fueros de Parga, Llanes y Puebla de Sanabria son los únicos fueros conservados que abordaban la regulación del delito de adulterio en esta familia foral, y a ellos dedicamos el presente estudio.

\section{El adulterio en los fueros de Parga y Llanes}

En primer lugar, transcribiremos lo que establecían al respecto de este delito o placer ilícito ${ }^{6}$ los fueros de Parga y Llanes, para después realizar los comentarios y análisis pertinentes, en aras de comprender las tramas de significación implicadas. En cuanto al primero de estos fueros, se disponía lo siguiente sobre el mencionado ilícito: "Si aliquis cum muliere aliena de [benedic]ciane comprehensus fuerit, moriantur ambo et perdant quantum habuerint. Et si fugerint, non succurrat illos ecclesia neque palacium alicuis potentis; et si aliquis illos amparaverit, cum ipsis criminosis pena sustineat" ${ }^{\prime}$.

Por su parte, la redacción del fuero de Llanes que se conserva establecía, en forma romanceada, lo que sigue: "Et aquel que con muger de bendicion fuere fallado, mueran ambos. Et si fugiesen, non les vala la Eglesia, nin palacio alguno, e non los ampare ninguno. E si alguno los amparar, aya tal pena como ellos".

En consecuencia, tenemos dos normas diferenciadas en ambas leyes, una primera, que describía sutilmente y en pocas palabras la conducta típica del delito de adulterio uxorio, establecía la condición personal de que la mujer delincuente fuere mujer de bendiciones ${ }^{9}$, obligaba a iniciar la acusación en caliente y, final-

${ }^{6}$ A. Rucquoi emplea la categoría de placer ilícito para enmarcar su estudio sobre diferentes delitos y transgresiones sexuales en la Edad Media española, entre las que se encontraba el adulterio, cfr. Rucquor, Adeline, Aimer das l'Espagne Médiévale. Plaisirs licites et illicites (Les Belles Lettres, 2008).

${ }^{7}$ F.Parga 15. Como aclaración, respecto de este fuero, empleamos la edición de MARTínEZ Martínez, Faustino (ed.), Antología de textos forales del antiguo reino de Galicia (siglos XII-XIV), en Cuaderno de Historia del Derecho, 10 (2003), pp. 314 ss.

${ }^{8}$ F.Llanes 14.

9 Para un estudio sobre la progresiva importancia del matrimonio de bendiciones en el derecho medieval peninsular y en la sociedad de la época, por influencia del cristianismo y del derecho eclesiástico, cfr. SANCRISTÓBAL IBÁN̄EZ, Miguel Ángel, El matrimonio en Portugal durante la baja Edad Media, en Edad Media: revista de historia, 5 (2002), pp. 161 ss., CARLÉ, María del Carmen, Apuntes sobre el matrimonio en la Edad Media española, en Cuadernos de historia de España, 63-64 (1980), pp. 115 ss., AzNAR GIL, Federico Rafael, La institución matrimonial en la Hispania cristiana bajo-medieval (1215-1563) (Salamanca, Universidad de Salamanca, 1989), Bermejo Castrillo, Miguel Ángel, Parentesco, matrimonio, propiedad y herencia en la Castilla altomedieval (Madrid, Universidad Carlos III de Madrid, 1996), pp. 135-147 y FERNÁNDEZ Regatillo, Eduardo, El Derecho matrimonial en las Partidas y en las Decretales, en Acta Congressus Iuridici Internationalis, Pontificium Institutum Utriusque Iuris (Roma, 1936), III, pp. 297 ss.

Respecto de este asunto, si bien existen fueros y códigos normativos que contemplaban expresamente el adulterio con la mujer desposada o con la mujer de juras en el derecho medieval peninsular previo a los fueros que aquí estudiamos, o de la primera mitad del siglo XIII, también hallamos una gran diversidad de fueros que no hacían expresamente mención a estas situaciones en la regulación del adulterio. Sobre este tema, véase una breve reflexión, pero interesante, en 
mente, prescribía la punición correspondiente por la conducta, que implicaba el ejercicio de la violencia santa y legítima del sistema judicial ${ }^{10}$. Esta punición, en el caso del fuero de Parga, implicaba, además de la pena de muerte, la pérdida de todo el patrimonio de los sujetos activos ${ }^{11}$. Y, en segundo término, observamos una norma que excluía toda posibilidad de amparo a los delincuentes en estos

RoldÁn Verdejo, Roberto, Los delitos contra la vida en los fueros de Castilla y León (La Laguna, Universidad de La Laguna, 1978), pp. 171-172. Respecto del primer grupo mencionado:

- El derecho romano contemplaba expresamente la situación de la desposada ante el delito de adulterio a causa de la regulación de la Lex Iulia de adulteriis coercendis, cfr. Digesto 48,5,14 (13).

- El Liber Iudiciorum, por influencia del derecho romano, contemplaba entre sus leyes también el adulterio de la mujer desposada en L. Iudiciorum 3,4,2 y 3,4,4.

- Respecto de la familia de fueros de Coria-Cima Coa, hoy no se conserva el fuero latino de Ciudad Rodrigo, anterior a los fueros de León-Benavente que nos interesan, pero su contenido puede conocerse a través de la reproducción realizada por el fuero de Alfaiates. A este respecto, apreciamos una cuestión relevante, en la medida en que en los fueros de esta familia hallamos la expresa mención a la mujer de juras en la regulación del delito de adulterio, cfr. F.Coria 59, F.Cáceres 64, F.Usagre 66, F.Castel-Rodrigo 3,28, F.Alfaiates 42, F.Castel-Melhor 97 y F.Castelo-Bom 61. En cuanto a la regulación y al sentido del matrimonio de juras en estos fueros, cfr. Dillard, Heath, La mujer en la Reconquista (Madrid, Editorial Nerea, 1993), pp. 174-175.

Respecto del segundo grupo:

- A esta configuración responde lo establecido en L.Iudiciorium 3,4,3.

- Dentro de la familia de Logroño, véase lo establecido por el fuero de Miranda del Ebro, cfr. F. Miranda 34, que únicamente mencionaba a la mujer velada.

- Véase lo dispuesto en la familia de fueros de Cuenca-Teruel en las leyes contenidas en las notas 19 y 20 . Téngase en cuenta que la mayoría de estos fueros se redactaron con certeza posteriormente a los fueros de la familia de León-Benavente que nos interesan, sin embargo, recogían un derecho supuestamente plasmado con anterioridad, que fue expandiéndose por la península a través de diversos focos normativos. En todo caso, sobre la cuestión problemática de la datación del derecho de esta familia foral y sobre las distintas hipótesis al respecto, véase Barrero García, Ana María, La familia de los Fueros de Cuenca, en Anuario de Historia del Derecho Español, 46 (1976), pp. 713 ss.

- Dentro del derecho catalán, véanse los siguientes fueros de la familia de fueros de Tortosa anteriores a los fueros que nos interesan: F.Lérida y F.Agramunt, así como, fuera de ella, cfr. U.Barcelona 110-112.

- Respecto de la familia de Jaca o los fueros de Jaca, cfr. F.Estella 51 y F.Jaca A 66 y 154.

- Respecto de la familia de Ávila, cfr. F.Penamacor, F.Proença, F.Egitania y F.Salvaterra.

- Respecto de la familia de Salamanca, cfr. F.Freixo, F.SantaCruz y F.Orrio, F.Sortehla y F.Menendo.

- Respecto del derecho portugués ajeno a las familias de Ávila y de Salamanca, sin ánimo de agotar la casuística, cfr. F.TorresNovas, F.Thomar, F.Ozezar, F.Palumbare y F.Auren, para la consulta de los cuales hemos empleado Herculano, Alexandre (ed.), Portugaliae Monumenta Historica, Leges et Consuetudines (Lisboa, Academia das Ciências de Lisboa, 1856), como para los restantes fueros portugueses aquí citados, salvo que se mencione otra fuente en el apartado 5 .

Por último, a los efectos de esta nota 9 , y respecto de los fueros portugueses sueltos, téngase en cuenta que, a pesar de su similitud y de que obviamente es una cuestión debatible, no calificamos como adulterio el delito de abandono conyugal femenino contenido en F.Cernanceli y F.Sabadeli.

${ }^{10}$ Sobre esta naturaleza sagrada y legítima de la violencia ordenada hacia los delincuentes por los jueces, y concebida bajo los parámetros de la pena pública, desde un análisis ya clásico de la sociología penal, cfr. GIRARD, René, La violencia y lo sagrado (1972, reimp. Barcelona, Anagrama, 1983).

${ }^{11}$ En todo caso, no es descartable que la ausencia de esta pena patrimonial en el fuero de 
fueros, de manera que incluso se excluía del derecho de asilo en los templos cristianos a los adúlteros.

En cuanto a la conducta típica, la acción sexual aparece sugerida en las expresiones equivalentes empleadas en ambos fueros ("Si aliquis cum muliere aliena de [benedic]ciane comprehensus fuerit [...]" y "Et aquel que con muger de bendición fuere fallado [...]"), que reproducen una fórmula que, si bien tenía variantes, era usual en la regulación de los delitos sexuales en el derecho peninsular de los siglos XII y XIII ${ }^{12}$, y que, dada su configuración, implicaba la necesidad de hallar in fraganti

Llanes se debiera simplemente a un error del copista de la redacción que se conserva del mencionado texto, y no respondiera a una decisión consciente del legislador.

En cuanto a los antecedentes respecto del detrimento patrimonial en los culpables a causa de su responsabilidad, véase como posible fuente lo dispuesto en el Liber Iudiciorum, que también prescribía la pérdida del patrimonio de los adúlteros, si bien en este caso se indicaba expresamente el destino de estos bienes, a favor del marido o esposo ofendido o de determinados descendientes, según las circunstancias, cf. L.Iudiciorum 3,4,2 y 3,4,12.

${ }^{12}$ Para una mejor explicación de la materia, dividiremos por familias de fueros nuestra explicación:

- En cuanto a la familia de Jaca y a los fueros de esta localidad, cfr. F.JacaA 65 respecto del delito del adulterio masculino (esta ley puede apreciarse también en posteriores redacciones de este fuero, como en F.JacaA $\left.{ }^{2} 48\right)$ y F.Estella 51 respecto del adulterio femenino. Téngase en cuenta que, en esta variante, no se menciona que los adúlteros fueran hallados, sino que fueran presos, que consideramos equivalente.

- Respecto de la familia de Cuenca-Teruel, véanse las siguientes normas que regulaban el ius occidendi sobre la mujer adúltera en sus fueros previos al siglo XIV, donde se aprecia una semejante construcción lingüística: cfr. F.Cuenca 11,28, Co.Valentino 2,1,23, F.Béjar 322, F.Zorita 252, F.Úbeda 28,1, F.Iznatoraf 250, F.Sabiote 251, F.Andújar 240, F.Huete 209, F.Alcaraz 4,28, F.Alarcón 236, F.Alcázar 236, F.Plasencia 68, F.Sepúlveda 73, F.Teruel 368 y F.Albarracín. Como puede comprobarse, únicamente mencionamos aquellos fueros de esta familia anteriores al siglo XIV, y, por lo tanto, dentro del período histórico de nuestro interés. Véase como ejemplo la redacción del Códice Valentino: "Qualquier que su muger fallare con otro faziendo fornicio $[\ldots] "$.

No obstante, mayor afinidad encontramos aún con la expresión empleada en la regulación de la castración en caliente del culpable en caso de fornicio ilícito con la hija de familia, en la medida en que no se especificaba que los culpables fueran hallados faziendo fornicio, en una elaboración jurídica que daba por supuesta la acción criminal, en función del contexto gramatical en el que había de interpretarse, cfr. F.Cuenca 319 (12.16), Co.Valentino 2,2,8, F.Béjar 371, F.Zorita 288, F.Úbeda 30,2, F.Iznatoraf 290, F.Sabiote 291, F.Andújar 270, F.Huete 240, F.Alcaraz 4,69, F.Alarcón 273, F.Alcázar 273, F.Plasencia 56, F.Teruel 396 y F.Albarracín. Y lo mismo cabe decir respecto del delito de fornicación entre miembros de diferentes leyes religiosas, cfr. F.Cuenca 300 (11,49), Co.Valentino 2,1,39, F.Iznatoraf 270, F.Zorita 272, F.Alarcón 246, F.Alcázar 246, F.Alcaraz 4,49, F.Andújar 482, F.Béjar 350, F.Úbeda 29,2, F.Sabiote 271, F.Sepúlveda 71, F.Brihuega 113, F.Plasencia 107, F.Huete 227, F.Teruel 386 y F.Albarracín.

Por último, más allá de estas normas, véase también esta construcción lingüística asociada a los delitos sexuales en las leyes de esta familia referidas en la nota 19.

- Respecto de la familia de Coria-Cima Coa, véase la redacción de las leyes contenidas en la nota 9. También en esta familia, respecto del delito de fornicación entre miembros de diferentes leyes religiosas, podemos apreciar una construcción lingüística semejante, en F.Coria 135, F.Usagre 395, F.Castel-Rodrigo 3,42, F.CasteloBom 113, F.Castel-Melhor 113 y F.Cáceres 386.

- Respecto de los fueros del siglo XIII de la familia de Lérida, cfr. F.Lérida 15 y F.Horta 22.

Más allá de estas familias de fueros, véase lo dispuesto en el Fuero Juzgo (cfr. F.Juzgo 3,4,3; $3,4,5$ y $3,4,6)$. Por otra parte, en el derecho alfonsí, de mediados del siglo XIII, apreciamos unas 
a los delincuentes para que pudiera iniciarse el proceso $^{13}$, o bien para aplicar la venganza en caliente, en otros fueros. Esta construcción lingüística no nos permite discernir la naturaleza específica de la relación sexual, pues no podemos concluir si la penetración anal o vaginal con el miembro viril era requisito necesario para la apreciación del tipo, o bien, cabían otras formas de comisión ${ }^{14}$. Pero ello no era extraño en la regulación de los delitos sexuales de este período, donde, por lo general, se empleaba un vocabulario poco preciso en la descripción de las conductas perseguidas, probablemente por una cuestión de recato por parte del legislador ${ }^{15}$.

Respecto de las posibles consecuencias negativas para los adúlteros por la comisión del llamado adulterio simple ${ }^{16}$, hemos de hacer constar que la respuesta punitiva para estos delincuentes en el derecho peninsular de la época no era uniforme, ya que en él encontramos tanto penas privadas o públicas tras el oportuno proceso, como, por otra parte, espacio abierto a la venganza privada en caliente en determinadas circunstancias. En concreto, en el Liber Iudiciorum hallamos,

construcciones emparentadas para regular el ius occidendi contra la mujer fornicaria en F.Real 4,7,6 y 4,17,1. Más alla del territorio castellano-leonés, cfr. F.G.Navarra 4,3,12, F.JaimeI 1156, F.Tortosa 9,3,5 y F.Fresno.

Por último, en cuanto a las características de los procedimientos judiciales tras prender a los sujetos activos hallados in fraganti en el derecho peninsular medieval, podrían citarse una pluralidad de obras, pero baste a estos efectos mencionar el trabajo de GARCía DE VALDEAVELLANO, Luis, El apellido. Notas sobre el procedimiento in-fraganti en el derecho español medieval, en Cuadernos de Historia de España, 7 (1947), pp. 67 ss.

${ }^{13}$ Véase cómo esta norma de los fueros de Parga de y de Llanes se separaba de lo dispuesto en L.Iudiciorum 3,4,3, que permitía la acusación en caso de adulterio por señales o presunciones.

${ }^{14}$ En todo caso, y aunque no podamos discernir la naturaleza específica de la relación sexual o erótica exigida, sí podemos emplear como referencia la interpretación ofrecida por las Leyes del Estilo, para establecer cuándo podía considerarse que los sujetos activos eran descubiertos en flagrante delito. En atención a lo dispuesto en este texto, se entendía que eran hallados en tal forma los que fueran sorprendidos "solos en uno, et desnudos" (cfr. L.Estilo 62).

${ }^{15}$ Sobre la imprecisión en esta materia en las fuentes jurídicas de la época, atribuibles al pudor, cfr. Mendoza GarRido, Juan Miguel, Delincuencia y represión en la Castilla bajomedieval (Grupo Editorial Universitario, 1999), pp. 238-245. Respecto de las manifestaciones lingüísticas relacionadas con la sexualidad en los fueros y códigos normativos de la Castilla medieval, cfr. Montero Cartelle, Enrique, La sexualidad medieval en sus manifestaciones lingüisticas: pecado, delito y algo más, en Clío \& Crimen, 7 (2010), pp. 49-54.

No obstante, en algunos fueros sí podemos hallar la descripción precisa de la acción sexual objeto de punición. Particularmente hemos de referirnos a la fazaña descrita en el Fuero Viejo de Castiella y en el Libro de los Fueros de Castilla respecto del hombre de Castro Urdiales que penetró vaginalmente con su mano a la víctima de la agresión, cfr. F.Viejo 2,2,2 y L.Fueros 303. Por otra parte, y aunque no se trate de un delito concebido como un hecho libidinoso, sino, más genéricamente, como un denuesto de hecho, en la familia de Cuenta-Teruel encontramos el ilícito de introducir un palo por el ano, penado con una multa, en F.Cuenca 338 (12,34), Co.Valentino 2,2,28, F.Béjar 393, F.Zorita 307, F.Úbeda 30,6, F.Iznatoraf 311, F.Sabiote 312, F.Andújar 286, F.Huete 259, F.Alcaraz 4,87, F.Alarcón 291, F.Alcázar 291, F.Plasencia 123, F.Teruel 398 y F.Albarracín.

${ }^{16}$ La distinción entre adulterio simple y adulterio estable o continuado en las leyes de los fueros castellano-leoneses fue establecida para una mejor comprensión de los diferentes delitos por Gacto Fernández, Enrique, La filiación ilegitima en la historia del Derecho español, en Anuario de Historia del Derecho Español, 41 (1971), pp. 907 ss. 
junto a la traditio in potestate de los delincuentes al marido ofendido tras el proceso penal y la consecuencia patrimonial adversa para los adúlteros, el amparo al ejercicio de la venganza privada contra éstos sin proceso previo, si fueron hallados in fraganti y siempre que se administrase en el acto ${ }^{17}$. Por su parte, si bien en los siglos XI y XII no encontramos mucha información dentro del derecho foral de la época ${ }^{18}$, ya en el siglo XIII sí observamos una pluralidad de casos interesantes, y así, en los fueros castellano-leoneses de la familia de Cuenca y Teruel podemos apreciar tanto la pena de muerte en la hoguera en caso de adulterio público ${ }^{19}$, como el amparo legal de la venganza privada a los delincuentes hallados in fraganti siempre que se administrase en el acto, en el adulterio privado ${ }^{20}$, como también se reconocía esta posibilidad en la familia de Coria-Cima Coa para el mismo delito ${ }^{21}$, además del ius occidendi reconocido luego del oportuno proceso en el fuero de Alcalá de Henares ${ }^{22}$. Fuera de los territorios de Castilla y de León, en el derecho de la Corona de Aragón hallamos dentro del fuero de Teruel semejantes normas respecto de las previstas con carácter general en los fueros de su familia en caso de adulterios públicos y privados ${ }^{23}$, mientras que diversas soluciones jurídicas fueron

${ }^{17}$ Para apreciar los términos en que fueron reguladas estas cuestiones y, en general, el delito de adulterio, en la compilación visigoda, cfr. L.Iudiciorum 3,4. Para un estudio riguroso sobre la materia, cfr. OsABA, Esperanza, El adulterio uxorio en la Lex Visigothorum (Madrid, Marcial Pons, 1997). Más allá de estas cuestiones, respecto de la influencia de la legislación visigótica en materia de adulterio en el derecho general de Castilla, cfr. COllantes DE TERÁN DE LA HERA, M. J., El delito de adulterio en el derecho general de Castilla, en Anuario de historia del derecho español, 66 (1996), pp. 201 ss.

${ }^{18}$ De la diversidad de fueros consultados durante nuestra investigación en materia de transgresiones sexuales en estos últimos años, sólo hemos hallado un caso reseñable a estos efectos dentro del territorio castellano-leonés, en el que, sin lugar a dudas, estemos ante la regulación y castigo de un delito de adulterio, y no ya de un delito de abandono conyugal. Nos referimos al fuero de Miranda del Ebro, donde apreciamos tanto el amparo legal a la venganza privada del marido, como una pena pública para el adúltero que escapase a ésta, cfr. F.Miranda 34

19 Cfr. F.Cuenca $276(11,25)$, Co.Valentino 2,1,20, F.Béjar 319, F.Zorita 249, F.Úbeda 28pr., F.Iznatoraf 247, F.Sabiote 248, F.Andújar 236, F. Huete 206, F.Alcaraz 4,25, F.Alarcón 233, F.Alcázar 233 y F.Plasencia 66.

Llamamos adulterio público a este delito, ya que el mismo era cometido fuera del hogar conyugal y su trascendencia desbordaba los límites familiares, por lo que correspondía imponer la pena pública de morir en la hoguera a los culpables y se excluía el ejercicio de la venganza privada (sobre esta exclusión y otras cuestiones relativas a este delito, cfr. RODRÍGUEZ GALLARDO, Francisco, El ius puniendi en delitos de adulterio (análisis histórico-jurídico), en Revista de Derecho Penal y Criminología, 5 (1995), pp. 881 ss.). Por el contrario, el adulterio privado de la nota siguiente era configurado como un delito cometido en la intimidad, descubierto por el marido, al que se le reconocía el ius occidendi contra el culpable sin reproche penal alguno, al tiempo que no se le otorgaba acción para iniciar un proceso penal contra los adúlteros.

${ }^{20}$ Cfr. F.Cuenca 11,28, Co.Valentino 2,1,23, F.Béjar 322, F.Zorita 252, F.Úbeda 28,1, F.Iznatoraf 250, F.Sabiote 251, F.Andújar 240, F. Huete 209, F.Alcaraz 4.28, F.Alarcón 236, F.Alcázar 236, F.Plasencia 68 y F.Sepúlveda 73.

${ }^{21}$ Para apreciar las leyes donde se reflejaban las condiciones en las que se permitía el ejercicio de esta venganza privada contra los adúlteros, cfr. nota 9.

22 Cfr. F.Alcalá 70.

${ }^{23}$ Cfr. Teruel 366, 368 y 396. No obstante, téngase en cuenta que en este fuero encontramos también penado el adulterio simple masculino, en F.Teruel 374, a diferencia de lo regulado 
empleadas en otros fueros de Aragón ${ }^{24}$, tanto como en el derecho navarro ${ }^{25}$, en el catalán ${ }^{26}$, en el valenciano ${ }^{27}$, así como en los fueros portugueses ${ }^{28}$. Por último, en cuanto a las normativas conciliares, éstas habían mostrado cierto interés desde la formación de los nuevos reinos cristianos hasta las primeras décadas del siglo XIII por la cuestión del adulterio ${ }^{29}$, pero, a partir de entonces ${ }^{30}$, y especialmente a partir del siglo XIV, se acentuó la preocupación por la materia ${ }^{31}$.

en el derecho castellano-leonés de esta familia. Respecto del adulterio simple masculino en el derecho peninsular, cfr. Gacto Fernández, Enrique, cit. (n. 16) y Fernández-Viagas Escudero, Plácido, La honra del marido como bien jurídico protegido en el delito de adulterio: Un estudio de las Partidas a la luz de sus antecedentes normativos y de su contexto jurídico, en Clio \& Crimen, 13 (2016), pp. 53 ss.

${ }^{24}$ Cfr. F.JacaA 65, 154 y 228, F.Estella 51 y V.Mayor 9,29.

${ }^{25}$ Cfr. F.Estella 51 y F.G.Navarra 4,3,12 y 6,9,4.

${ }^{26}$ Véase la pena infamante de F.Lérida y F.Agramunt, dentro de la familia del fuero de Tortosa, como la prevista en F.Tortosa 9,3,5 y la sanción pecuniaria de U.Barcelona 110-112. Más allá de estos fueros, véanse las diferentes mutilaciones y penas corporales previstas en las Cortes de Barcelona de 1064 para los adúlteros, cfr. Cor.Barcelona 90.

${ }^{27}$ Cfr. F.Jaime I 1156.

${ }^{28}$ Dividiremos por familias de fueros estas leyes para una mejor explicación:

- En cuanto a la familia del fuero de Ávila, véanse las consecuencias civiles y patrimoniales del delito en los fueros mencionados en la nota 9.

- En cuanto a la familia del fuero breve de Salamanca, además de la regulación del delito contenida en los fueros de Sortehla y de Menendo, que comparte redacción con los fueros de la familia de Ávila que regulaban esta materia, véase lo dispuesto en los fueros de Freixo, Santa Cruz y Orrio, que establecían, por clara influencia del Liber Iudiciorum, la traditio in potestate de los delincuentes al marido, para que éste pudiera tomarse venganza sobre ambos sin reproche penal alguno.

Más allá de estas dos familias, y sin ánimo de agotar la casuística, véase la pena pecuniaria a la adúltera en la regulación del delito de adulterio en los fueros de Thomar, OZezar, Palumbare, Auren y Torres Novas. Por otra parte, véase cómo en el fuero de Fresno a la mujer que tenía relaciones adúlteras con un hombre casado, además de imponérsele la pena pecuniaria, se le asignaba la pena de muerte en la hoguera.

${ }^{29}$ A los efectos del presente estudio, conviene citar expresamente el concilio de Coyanza, del siglo XI, tanto por ser un documento leonés anterior a los fueros de Parga y de Llanes que estamos analizando, como por su contenido, ya que en él se ordenaba a los arcedianos y a los capellanes que llamasen a confesión a los adúlteros y a otros pecadores sexuales, para imponerles la oportuna penitencia. De no responder estos pecadores a dicha llamada, habían de ser excomulgados y no podrían entrar en los templos en adelante, cf. Co.Coyanza 4. Por otro lado, también reúne cierto interés para nosotros, por cuanto se preocupa de la cuestión del adulterio y de la respuesta ante tal pecado, el canon 9 del concilio de Palencia de 1129.

${ }^{30}$ Si bien fuera de los territorios de León y de Castilla, encontramos a mediados del siglo XIII un concilio enormemente interesante a los efectos del presente artículo, por cuanto se establecía la imposición de una penitencia pública para los culpables de adulterio, en el concilio de Tarragona de 1243, cfr. Co.Tarragona 2.

${ }^{31}$ Para una aproximación a estas fuentes, cfr. Álvarez Bezos, María Sabina, Violencia contra la mujer en la Castilla del final de la Edad Media (Universidad de Valladolid, 2015), pp. 27 y 65-66 y Arranz GuZMán, Ana, Imágenes de la mujer en la legislación conciliar, en Las mujeres medievales y su ámbito jurídico (Madrid, Universidad Autónoma de Madrid, 1983), pp. 33 ss. Más allá de los textos peninsulares, para un estudio de la cuestión del adulterio en el derecho eclesiástico europeo, podría citarse una gran variedad de obras, pero, para una primera panorámica, baste mencionar BRUNDAGE, James A., Adultery and Fornication: A Study in Legal 
En consecuencia, en la península existía una regulación heterogénea sobre la respuesta apropiada frente al adulterio simple de la mujer, heterogeneidad que también apreciamos para este particular en las fuentes no jurídicas del período, lo que podemos constatar en la literatura de origen oriental, ya sea en Disciplina Clericalis $^{32}$, Calila e Dimna ${ }^{33}$, Bocados de Oro ${ }^{34}$ y Sendebar ${ }^{35}$, así como en la propiamente castellana, como en las Cantigas de Santa María ${ }^{36}$ y la Vida de Santo Domingo de $\operatorname{Silos}^{37} \mathrm{y}$, dentro de la historiografía, en la Crónica najerense ${ }^{38}$, De

Theology, en Bullough, Vern L. y Brundage, James (eds.), Sexual Practices \& the Medieval Church (New York, Prometheus Books, 1994), pp. 129 ss. y La ley, el sexo y la sociedad cristiana en la Europa medieval (México D.F., Fondo de cultura económica, 2000)

32 Véase el ejemplo XIV, en el que el marido ofendido por el adulterio uxorio amenaza a su mujer con el repudio y con la vergüenza de ser acusada ante sus padres.

${ }^{33}$ Respecto de este cuerpo literario:

- Véanse un caso de venganza privada como reacción al adulterio uxorio en Calila pp. 139-140.

- Véase la falsa acusación de adulterio sobre una mujer, para que fuera condenada a la muerte, así como la reacción en caliente del marido en Calila pp. 273-279.

${ }^{34}$ Podemos apreciar la norma de que por fornicio con mujer (entendemos que adulterio), se azotase al varón y se lapidase a la mujer, cfr. Bocados f. 8v.

${ }^{35}$ En esta colección de cuentos sobre engaños de las mujeres apreciamos en el cuento XIV la falsa acusación de adulterio a un varón por parte de su mujer, a causa de lo cual éste fue despojado de sus bienes, de sus títulos de honor, quedó deshonrado y «por la calumnia de su mujer, soportó el castigo de los adúlteros».

${ }^{36}$ En este repertorio literario apreciamos dos cantigas que nos aportan información de interés:

- La cantiga 5 narra la falsa acusación de adulterio sobre una emperatriz romana por su propio cuñado. A causa de esta acusación, la emperatriz fue primero encarcelada en una torre por orden de su propio cuñado y luego condenada a muerte por su marido, cuando tuvo conocimiento de la acusación. No obstante, la Virgen se apiadó de la emperatriz en el último momento y la salvó tanto de ser ejecutada en el bosque, como de la violación que pretendían infringirle los verdugos, como acto de repulsa.

- La cantiga 186 narra otra falsa acusación de adulterio, tramada por una madre que pretendía hacer creer a su propio hijo que su mujer había tenido relaciones sexuales con un siervo musulmán, al que había ordenado que se acostara junto con ella, mientras ésta dormía. El hijo, cuando presenció que ambos compartían lecho en la noche, pretendió tomarse la venganza por su mano, pero su madre lo persuadió para avisar a un juez que resolviese la cuestión conforme a derecho. Éste, tras presenciar la escena, dictó sentencia de muerte para ambos. No obstante, la Virgen intervino durante la ejecución, y salvó a la mujer inocente poco antes de ser quemada en una hoguera, junto con su siervo.

${ }^{37}$ En este texto de Gonzalo de Berceo se indica la siguiente máxima: "No hacer fornicio salvo con la propia mujer, para no ser dañado", cfr. DomingoSilos p. 442.

${ }^{38}$ En este texto leemos la historia de la mujer del rey Sancho Garcés III, que fue falsamente acusada de adulterio por su hijo García. No obstante, al probarse su inocencia, la reina se libró de la infamia y de la condena, cfr. C.Najerense 3,2. 
Rebus Hispaniae ${ }^{39}$, General Estoria ${ }^{40}$, Primera Crónica Genera ${ }^{41}$ y Gran conquista de $U_{\text {Utramar }}^{42}$, fuentes que nos ofrecen un amplio repertorio de reacciones o castigos ante el adulterio simple, correspondientes a los siglos XII y XIII.

Así pues, la pena de muerte para los adúlteros no era extraña en el entramado jurídico peninsular de la época, ni tampoco en el amplio repertorio literario anterior al siglo XIV, que nos ayuda a construir las tramas de significación de la época que nos ocupa, y que nos describe las diferentes maneras de separación ritual de la comunidad que implicaba el adulterio uxorio para la mujer, revestida de impureza a causa de su acto ${ }^{43}$. No obstante, la mencionada familia de Cuenca-

39 En este texto hallamos la misma historia de la falsa acusación a la reina contada en el anterior, pero con diversos añadidos. Entre estos añadidos se nos cuenta cómo el rey envió presa a su mujer al castillo de Nájera, mientras que se averiguase la verdad de los hechos (cfr. DRH. 5,26).

${ }^{40}$ En la General Estoria encontramos varios casos de interés, de entre los que podemos destacar una gran variedad procedente de diferentes tradiciones, con las ramas judaica y griega como principales:

- En el capítulo Levítico de esta colección se establecía, por expresa derivación bíblica, la pena de muerte para los adúlteros tanto en caso de adulterio de la mujer como del marido, cfr. GE. 1,2: 588. Por otra parte, en el mismo capítulo se indicaba la misma pena que la antedicha para quien realizara adulterio con la mujer del judío, cfr. GE. 1,2: 589-590.

- En el capítulo Números se describen las maldiciones que deberían recaer sobre la mujer adúltera, cfr. GE. 1,2: 673-674.

- En el capítulo Deuteronomio, siguiendo lo establecido en anteriores capítulos, se prescribía la muerte para los adúlteros, cfr. GE. 1,2: 908, así como también encontramos la declaración de que es maldito "qui duerme con muger de omne de su ley", cfr. GE. 1,2: 921, por lo que el crimen convertía en maldito al infractor y además lo condenaba a la muerte.

- En el capítulo de Josué se afirmaba que el adulterio es un pecado mortal (cfr. GE. 2,1: 117 ), por lo que su comisión podía condenar al infierno a los pecadores.

- Dentro de las narraciones de adulterios procedentes de la cultura griega, no encontramos el establecimiento genérico de leyes penales sobre el particular, ni tampoco una aproximación teológica, como en el anterior caso, pero sí apreciamos narraciones de casos particulares que revisten interés, dado que muestran tanto reacciones privadas en venganza por el crimen, como penas decretadas por la autoridad pública en respuesta. A este respecto, y sin ánimo de agotar la casuística, cfr. GE. 2,1: 212-213 y 283-286 y GE. 5,1: 318.

${ }^{41}$ En esta colección historiográfica encontramos algunos capítulos que nos añaden información de interés al respecto:

- El capítulo 172 narra la reacción en caliente de un marido ultrajado por el emperador de Roma, quien recibió graves heridas a causa de los hechos.

- El capítulo 791 narra la falsa acusación de adulterio sobre una reina, que estuvo presa en el castillo de Nájera hasta que su marido tuvo conocimiento de la falsedad de la acusación y ordenó su liberación.

${ }^{42}$ Dentro de este cuerpo historiográfico, encontramos inserto, adaptado a la lengua castellana, el conocido relato de El caballero del cisne, en el que se hace mención a una ley por virtud de la cual las mujeres que conciben más de un hijo en un mismo parto han de tener la consideración de adúlteras y, por ende, han de morir en la hoguera, cfr. GCU. 1,51; 1,53; 1,61 y 1,62.

${ }^{43}$ En cuanto a la adquisición de la impureza por la comisión de graves delitos y la necesidad de imponer la pena de muerte, como medida de separación radical entre el ser devenido en impuro y la comunidad, bajo un análisis de sociología de las religiones, cfr. CAILloIs, Roger, El hombre y lo sagrado (1939, reimp. México D.F., Fondo de Cultura Económica, 1984), pp. 43-49.

Con un carácter más genérico, sobre la necesidad de mantener separadas las cosas sagradas (ya sean puras o impuras) y profanas por un abismo cargado de significado, véanse los trabajos 
Teruel preveía esta pena corporal exclusivamente para el adulterio público ${ }^{44} \mathrm{y}$, además, a diferencia de los fueros estudiados de León-Benavente, como vimos, concretaba su forma de ejecución mediante el mortal castigo del fuego ${ }^{45}$. Por otra parte, la fazaña de la mujer falsamente acusada de adulterio del fuero de Jaca, que mencionaba la pena de muerte para la adúltera, no nos refería la pena para su amante, ni respondía al derecho aplicado por los jueces hispánicos, sino que recogía una influencia jurídica del derecho oriental ${ }^{46}$.

Es por ello que, a pesar de los precedentes en materia de adulterio y de las particularidades del entramado cultural del siglo XIII, conviene buscar una fuente de esta regulación fuera del derecho peninsular. Y esta fuente podemos hallarla concretamente en una falsa ley atribuida a la Lex Iulia de adulteriis coercendis por la legislación justinianea, y según la cual correspondía la pena muerte para ambos

ya clásicos de Отто, Rudolf, Lo santo. Lo racional y lo irracional en la idea de Dios (Madrid, Revista de Occidente, 1965) y DuRKheIm, Emile, Las formas elementales de la vida religiosa (Buenos Aires, Schapire, 1968), así como otros posteriores, también de enorme relevancia en los estudios antropológicos y sociológicos del fenómeno religioso, que abordan esta separación de los dos planos del mundo y la construcción de tabúes que resguarden lo profano del contagio, como son los de Eliade, Mircea, Lo sagrado y lo profano, (4a edición, Barcelona, Paidós, 2014), Leeuw, Gerardus van der, La fenomenología de la religión (México-Buenos Aires, Fondo de Cultura Económica, 1964) y Widengren, Geo, Fenomenología de la religión (1945, reimp. Madrid, Ediciones Cristiandad, 1976).

Por otra parte, nótese que la separación de la mujer adúltera en este contexto cultural no sólo acontecía por el ejercicio de la venganza homicida sobre la misma, o por la aplicación de la pena de muerte prevista en estas fuentes, o bien por la pena de encierro en un monasterio, que recogían las Partidas (cfr. Partidas 7,17,15), por influjo del derecho justinianeo (cfr. Nov. Justiniano 128,10 y Cod.Justiniano 9,9,30 aut.), sino que la sociedad de la época con frecuencia excomulgaba verbalmente a estas mujeres a través del denuesto, a causa del reproche social que generaba su delito. En este sentido, téngase en cuenta que en los fueros municipales castellanoleoneses encontramos frecuentemente los términos puta, ençenguladera u otros semejantes en la legislación penal en materia de denuestos, como se comprueba en SERRA Ruíz, Rafael, Honor, honra e injuria en el derecho medieval español (Murcia, Sucesores de Nogués, 1969), Castillo Lluch, Mónica, De verbo vedado: consideraciones lingüisticas, en Cahiers de linguistique et de civilisation hispaniques médiévales, 27 (2004), pp. 23 ss., y Arauz MERCADO, Diana, Solteras, casadas y viudas. La condición jurídica de las mujeres castellano-leonesas en la normativa penal (siglos XII-XIV), en Val Valdivieso, María Isabel del y MartíneZ Sopena, Pascual (coords.), Castilla y el mundo feudal. Homenaje al profesor Julio Valdeón (Valladolid, Junta de Castilla y León-Universidad de Valladolid, 2009), pp. 323 ss., entre otros. Esta reiteración de las mismas voces en los fueros, que hacían escarnio de la mujer aludiendo a su promiscuidad, nos marca, precisamente, lo frecuente del empleo de estos mismos términos u otros emparentados semánticamente en el campo social para denostar a las mujeres, mediante acciones verbales de excomunión simbólica. En todo caso, en la mayoría de los fueros de la familia de fueros de Cuenca-Teruel, el empleo de estos denuestos contra las mujeres verdaderamente promiscuas, aunque se realizaran directa y públicamente, quedaba exento de pena alguna, cfr. F.Cuenca 280 (11,29), Co.Valentino 2,1,24, F.Andújar 241, F.Alcaraz 4,29, F.Zorita, 253, F.Alarcón 237, F.Alcázar 237, F.Úbeda 28.2, F.Iznatoraf 251, F.Plasencia 70, F.Sabiote 252 y 253, F.Teruel 370 y F.Albarracín.

${ }_{44}$ Respecto de la diferencia entre adulterio público y privado en estos fueros, cfr. nota 19.

${ }^{45}$ Cfr. nota 19.

${ }^{46}$ Cfr. Santomá Juncadella, Luis, El milagro de la mujer lapidada. Critica literaria de la versión en occitano cispirenaico aragonés, en Revista de Filología Románica, 27 (2010), pp. 285 ss. 
adúlteros, considerados como sacrílegos del matrimonio ${ }^{47}$. Así pues, en una ley inexistente, pero afirmada como cierta y atribuida al derecho romano occidental por los juristas justinianeos, encontramos la fuente principal para interpretar dicha pena, pues, presumiblemente, los legisladores de Parga y Llanes tenían ante sí la obra jurídica de Justiniano en la regulación de este delito, como comprobaremos a lo largo del presente artículo. De esta manera, disponemos de un delito y de una pena equiparables en esta ley recogida por el derecho romano oriental, así como la razonable deducción de que el legislador foral empleaba estas fuentes jurídicas extra peninsulares en la regulación en materia de adulterio.

En cuanto a la segunda norma ya referida, que excluía toda posibilidad de amparo a los adúlteros bajo la misma pena de muerte ${ }^{48}$ y proclamaba la supresión del derecho de asilo a los mismos, su fuente principal se encuentra también en este derecho romano oriental, ya cristianizado, y no en el derecho castellano o leonés previo $^{49}$. Téngase en cuenta que, aunque en el Código de Justiniano leamos que "nadie puede sacar por la fuerza a quien se refugie en las iglesias" 50 , en una regulación sobre el derecho de asilo heredera de anteriores leyes imperiales ${ }^{51}$, en las Novelas de este emperador se establecía una excepción a esta regla general que afectaba explícitamente a los adúlteros, expresada en los siguientes términos: "Los adúlteros no pueden refugiarse en lugares santos" 52 .

47 Cfr. Cod.Justiniano 9,9,30 e Instituciones 4,18,4 (téngase en cuenta que en la anterior norma, que es la más parecida a la de los fueros de Llanes y Parga, no se hacía mención a la forma de ejecución del castigo, mientras que en esta segunda se mencionaba la muerte por espada). Sobre la inexistencia de esta norma en la Lex Iulia y la falsa atribución del derecho justinianeo, cfr. CANTARElla, Eva, Según Natura: la bisexualidad en el mundo antiguo (Madrid, Akal, 1991), p. 186.

${ }^{48}$ En este punto, J. I. Ruiz de la Peña Solar entiende, acertadamente, que quienes amparasen a los adúlteros habían de ser concebidos, de acuerdo con estas leyes, como encubridores del delito, cfr. Ruiz DE LA PeÑa Solar, Juan Ignacio, La condición de la mujer a través de los ordenamientos juridicos de la Asturias medieval (siglos XII al XIV), en Las mujeres en las ciudades medievales (Madrid, 1984), pp. 68-69.

${ }^{4}$ No obstante, téngase presente que, dentro del vasto derecho foral, también podemos apreciar la prohibición de amparo al delincuente por un particular. En este sentido, véase una prohibición semejante a la aquí expuesta en la familia de fueros de Coria-Cima Coa, pero sólo para el caso de la mujer y siempre que ésta hubiera abandonado a su marido, cfr. F.Coria 64, F.Cáceres 70, F.Usagre 72, F.Castel-Rodrigo 4,3, F.Alfaiates 49, F.Castel-Melhor 135 y F.Castelo-Bom 65.

${ }^{50}$ Cfr. Cod.Justiniano 1,12,2.

${ }^{51}$ Sobre este particular, cfr. Gortázar Rotaeche, Cristina, J., Derecho de asilo y no rechazo del refugiado (Madrid, Dykinson, 1997), p. 47.

${ }^{52}$ Cfr. Novelas 17,7. A este respecto, contémplese también lo dispuesto en la norma contenida en Novelas 113,15. Siglos después, en el siglo XIII, véase esta misma exclusión de los adúlteros respecto del derecho de asilo en la Glosa ordinaria al Decreto de Joannes Teutonicus, cfr. Glos. ord. C.17 q.4 c.6.

Para un estudio de esta figura jurídica del asilo en los templos cristianos al delincuente durante el derecho previo a la Edad Moderna, con especial detenimiento en la regulación peninsular, véanse las siguientes obras de referencia, SANZ GonZÁlEZ, Mariano, Derecho de asilo: ¿Misericordia o justicia?, en Revista española de derecho canónico, 51-137 (1994), pp. 477 ss., Gortázar Rotaeche, Cristina, J., cit. (n. 51), Luque Talaván, Miguel, La inmunidad del sagrado o el derecho de asilo eclesiástico a la luz de la legislación canónica y civil indiana, en MAR- 
Ciertamente, con el Liber Iudiciorum se nos presentan en el derecho peninsular excepciones al reconocimiento del derecho de asilo para determinados delincuentes $^{53}$, pero la inclusión de los adúlteros entre estas excepciones es un elemento que nos habla de una influencia procedente del exterior, de ese derecho común que durante este período histórico fue empapando las legislaciones de la Europa occidental. Influencia que, por otra parte, fue recibida en esta familia foral de León-Benavente con varias décadas de antelación a la regulación del adulterio en las Partidas, de evidente y reconocida influencia romana ${ }^{54}$.

Respecto de los bienes jurídicos protegidos ante el ilícito, sólo en la época de Alfonso X éstos se mencionarán expresamente en la regulación del adulterio en la España medieval ${ }^{55}$. No obstante, no resulta difícil dilucidar al menos el principal de estos valores digno de defensa si realizamos una interpretación sistemática de estos fueros y conectamos la regulación del adulterio con la de los denuestos. De esta forma, podemos apreciar como el denuesto de cornudo era considerado como uno de los insultos a los que el legislador otorgaba relevancia penal en el derecho de esta familia de fueros ${ }^{56}$, como también ocurría en las importantes familias de fueros de Cuenca-Teruel y Coria-Cima Coa, entre otras ${ }^{57}$, y ello nos habla, precisamente, de la identidad deteriorada en el campo social de los maridos engañados por sus mujeres y del atentado contra su honor que suponía el delito de adulterio bajo este entramado simbólico, en tanto que el honor del varón se hacía depender de la fidelidad sexual de su mujer ${ }^{58}$. Esta dependencia se hace aún más evidente en la literatura no jurídica de la época, en especial en las llamadas cantigas de escarnio y maldecir gallego-portuguesas, que denigraban a los maridos engañados por sus parejas en clave de humor, presentándolos como seres pusilánimes ${ }^{59}$, así

tínez López-Cano, María del Pilar y Cervantes Bello, Francisco Javier (coords.) Los concilios provinciales en la Nueva España. Reflexiones e influencias (México D. F., Universidad Autónoma de México-Benemérita Universidad Autónoma de Puebla, 1995), pp. 253 ss. y Valladolid, Antonio, Disertacion del origen del asylo, e inmunidad de los Templos (Madrid, 1773).

53 Cfr. L.Iudiciorum 9,3,4.

${ }^{54}$ En este sentido, véase cómo la mención a los sabios antiguos de este título es una mención a los juristas romanos, conectando la ley I de dicho título con Cod.Justiniano 9,9,1 y su ley XIV con Dig. 48,5,24 (23).

55 Cfr. Partidas 7,17,1. Sin embargo, más allá de los textos jurídicos, los bienes dignos de protección a causa de este delito también aparecen descritos en GE. 1,2: 250 y 588.

56 Cfr. F.Parga 12, F.Llanes 13 y F.Milmanda 20.

57 Cfr. nota 43, para encontrar referencias bibliográficas sobre el particular.

58 Sobre este particular, cfr. MADERo, Marta, Manos violentas, palabras vedadas: la injuria en Castilla y León (siglos XIII-XV) (Madrid, Taurus, 1992), p. 106, PITT-Rivers, Julian, La enfermedad del honor, en Anuario IEHS: Instituto de Estudios histórico sociales, 14 (1999), p. 240, Gauvard, Claude, La fama, une parole fondatrice, en Médiévales, 12-24 (1993), p. 11 y Rodríguez Ortíz, Victoria, Historia de la violación. Su regulación juridica hasta fines de la Edad Media (Madrid, Consejería de Educación y Cultura, 1997), p. 244.

59 Cfr. CEM. 76, 106, 182, 185, 210, 212, 227, 269, 296, 353, 355, 360, 361, 369, 412 y 414. Respecto del carácter pusilánime atribuido al marido engañado en estas cantigas, cfr. CABANES JimÉnEZ, Pilar, El deseo femenino a la luz de algunas composiciones literarias medievales, en Lemir, 9 (2005).

Siguiendo la terminología goffmaniana, el estigma del marido tendría entonces como causa un defecto del carácter, ya que se derivaría, en última instancia, de su propia incapacidad para 
como también apreciamos este atentado al honor del varón en otros textos de diferente naturaleza durante el siglo XIII por la misma causa ${ }^{60}$. A este respecto, mencionaremos una cita del Libro de los doce sabios, de la primera mitad del siglo XIII, que aconseja al príncipe no cometer adulterios precisamente para no provocar deshonras en los maridos, así como males contra su propia persona y otros daños en su reino, en los siguientes términos: [...] E commo en espejo se catan las gentes en el príncipe o regidor casto, e amánselo e lóanlo e cobdícianle todo bien e ruegan a Dios por su vida, e no han dubda que les tomará las mujeres nin las fijas nin les fará por ende desonrra nin mal. E es muy cercano salvamiento del alma e maravilloso loor al mundo, e es estranna sennoría e gracia de Dios en las batallas, commo munchas vezes ayamos visto los príncipes castos ser vencedores y nunca vencidos. E tomemos enxenplo en el duque Godufre e en otros munchos príncipes, quántos e quán grandes fechos e maravillosas cosas fizieron e acabaron, por la castidad, lo qual las estorias maravillosa mente notifican. E por la luxuria vimos perdidos munchos principes e reyes, e desheredados de sus reynos, e munchas muertes e desonrras e perdimientos, asi de cuerpos commo de almas, de que damos enxenplo en el rey David, el destruimiento que Dios fizo por su pecado, e en el rey Salamón que adoró los idolos, e en Aristótiles e en el Vergilios. E en el rey Rodrigo que perdió la tierra de mar a mar, e en otros reyes e principes e sabidores que sería luengo de contar, de que las estorias dan testimonio ${ }^{61}$.

En consecuencia, tanto la interpretación sistemática, como la interpretación histórica y la sociológica, nos presentan al honor del marido ofendido por el adulterio como el principal bien jurídico digno de protección en este delito, dentro de este contexto jurídico y simbólico de la época, si bien no como el único valor agredido por el acto de lujuria ${ }^{62}$.

\section{El adulterio en el fuero de Puebla de Sanabria:}

\section{LA OBRA DE LOS JURISTAS ALFONSÍES}

Los fueros de Villafranca del Bierzo y de Puebla de Sanabria forman una pareja de fueros dentro de la vasta rama del derecho benaventano, que beben de un mismo texto foral, hoy desconocido ${ }^{63}$, y que, en consecuencia, presentan enormes similitudes entre sí. Sin embargo, en el presente apartado analizaremos una de sus divergencias, consistente en la regulación de la cuestión del adulterio en

controlar a su propia mujer. Sobre el estigma y las causas de surgimiento del mismo, cfr. GoFFMAN, Erving, Estigma: La identidad deteriorada (1963, reimp. Buenos Aires-Madrid, Amorrortu, 2006).

${ }^{60}$ Respecto de la historiografía alfonsí, cfr. GE. 1,2: 588 y 637 y GE. 3,1: 237, y, particularmente, véase cómo el conde García Fernández se sabe deshonrado por el adulterio continuado de su mujer, en el relato épico de La condesa traidora, en la versión de PCG. 732. Por otra parte, en cuanto a la literatura sapiencial de origen oriental, cfr. Sendebar 14, y en cuanto a la de producción castellana, cfr. L.12Sabios 7.

61 L. 12 Sabios 7.

${ }^{62}$ Para una primera aproximación a esta cuestión, del honor como bien jurídico, si bien específicamente referida al delito de adulterio en las Partidas, cfr. FERNÁNDEZ-ViagAs EsCUdERO, Plácido, cit. (n. 23).

${ }^{63}$ Cfr. García-Gallo de Diego, Alfonso, El fuero de León. Su historia, textos y redacciones, en Anuario de Historia del Derecho Español, 39 (1969), p. 45. 
el fuero de Puebla de Sanabria, ausente completamente del fuero de Villafranca. Téngase en cuenta que el primero de estos dos fueros fue aprobado en 1220 por Alfonso IX, pero Alfonso X lo confirmó en 1263, introduciendo algunas novedades en su derecho ${ }^{64}$. En el presente artículo comprobaremos cómo la regulación en materia de adulterio del fuero de Puebla de Sanabria constituye una de estas modificaciones, que no responde a la tradición jurídica de esta familia foral, sino a los parámetros del derecho alfonsí en materia de adulterio y analizaremos esta regulación en el contexto de la época.

En concreto, leemos en el fuero de Puebla de Sanabria lo siguiente: “La mujer que morare en Sanabria non sea presa nin asechada sin su marido; pero tenemos nos por razón e por derecho que si sabido fuere en verdad que ella faz tuerto a su marido, non seyendo él en la tierra, sea recabdada e ninguna justicia della non se faga fasta que venga el marido, e entoz el marido puédela acusar, o perdonar si quiere”.

La primera parte de la ley ("la mujer que morare en Sanabria non sea presa nin asechada sin su marido”) articula una exención de jurisdicción respecto de la mujer casada en ausencia de su marido que no es original del fuero que Alfonso $\mathrm{X}$ confirma, sino que también se hallaba en diversos fueros de la época, particularmente en la familia de León-Benavente ${ }^{65}$. Sin embargo, lo contrario ocurre con la excepción prevista en el resto de la redacción, que, como ya señaló J. Rodríguez, constituye un caso único en la familia de fueros que nos ocupa, sin igual siquiera en el fuero de Villafranca del Bierzo ${ }^{66}$. Por nuestra parte, al comentario del mencionado jurista, habría que añadir que tampoco encontramos la redacción de esta norma en ninguna de las familias de fueros breves o extensos del derecho peninsular previo al siglo XIV, ni tampoco en los restantes fueros de este período consultados durante nuestra trayectoria investigadora.

Dada su originalidad en el derecho que nos ocupa, y su relación con el delito de adulterio, es, pues, en esta parte de la redacción en la que hemos de centrar nuestra atención. En cuanto a la naturaleza del ilícito que se regula y que permite la detención de la mujer, no nos cabe duda de que estemos ante un caso de adulterio uxorio, dado el empleo de la voz tuerto. Y es que según los diccionarios contemporáneos del español medieval dicha voz estaba asociada, entre sus diferentes acepciones, a un hecho dañino o injurioso ${ }^{67}$. Pero un estudio del término

${ }^{64}$ A este respecto, precisamente porque Alfonso X introdujo algunas modificaciones respecto del texto original y desconocido en latín (cuestión reconocida por el propio rey en su confirmación y traducción del fuero a la lengua romance), resulta imposible conocer con precisión y de forma indubitada la redacción original en determinados puntos. Respecto de la política foral de Alfonso X podría citarse una pluralidad de obras, pero a estos efectos, y para una primera aproximación, cfr. GONZÁLEZ JimÉNEZ, Manuel, Sobre fueros, concejos y política municipal de Alfonso X, en II Congreso de Historia de Albacete: del 22 al 25 de noviembre de 2000 (Albacete, Instituto de Estudios Albacetenses “Don Juan Manuel”, 2002), pp. 11 ss.

${ }^{65}$ Con algunas modificaciones en su redacción, cfr. F.León 53, F.Villavicencio, F.Castrocalbón 23, F.Rabanal 8, F.Laguna 16 y F.Villafranca 16.

${ }^{66}$ Cfr. Rodríguez Fernández, Justiniano, Los fueros del reino de León (León, Ediciones Leonesas, 1981), p. 176.

${ }^{67}$ Cfr. Cejador y Frauca, Julio, Vocabulario medieval castellano (Madrid, Visor Libros, 1990), p. 398 y Alonso, Martín, Diccionario medieval español: desde las Glosas Emilianenses 
en su contexto, dentro del derecho castellano-leonés, nos arroja un significado más preciso respecto de las relaciones maritales, consistente en el daño o la injuria que hace el cónyuge a su par no guardando la fidelidad sexual, como se corrobora tras la lectura de este término en el Fuero Juzgo, las Partidas y otras fuentes ${ }^{68}$, por lo que estamos sin duda alguna ante un caso de adulterio uxorio.

Bajo esta calificación a la que nos conduce la semántica, y de acuerdo con el fuero, una vez que se tuviera conocimiento de la comisión del ilícito no estando el marido en la tierra, entonces la mujer debía ser prendida, pero no podía interponerse contra ella acusación alguna por su acto hasta que regresase su cónyuge, que era el único facultado para perdonarla o bien para acusarla. En cuanto a esta acusación, al igual que F. Martínez Marina ${ }^{69}$ y que L. Arrazola ${ }^{70}$, consideramos que se trataría de una acción de derecho procesal penal, aunque nada se aclare expresamente al respecto. En este punto, bien podría interpretarse que la ley no se refería a una acción de esta naturaleza, sino al ejercicio de una acción de divorcio, ya que el término acusación es empleado por este mismo legislador precisamente para aludir a la acción de divorcio en las Partidas ${ }^{71}$, y que, en segundo lugar, en el fuero de Sanabria no se regulaba la pena por el delito de adulterio, lo que podría apoyar la interpretación de que estuviésemos ante una acción de divorcio, que debiera sustanciarse en la jurisdicción eclesiástica. No obstante, no defendemos dicha interpretación por un análisis comparado que nos sugiere una conclusión diferente. En este sentido, téngase en cuenta lo dispuesto por el propio Alfonso $\mathrm{X}$ en el Fuero Real, según lo cual, la prisión para asegurar la comparecencia en juicio por cuestiones de derecho civil funcionaba como una última ratio y de

y Silenses (s. X) hasta el siglo XV (Salamanca, Universidad Pontifica de Salamanca, 1986), p. 1606. Concretamente, respecto de los diccionarios o glosarios de términos alfonsíes, cfr. PÉREZ Mozún, Diego, Diccionario alfabético y ortográfico de las voces que en sus célebres Partidas usó el rey don Alfonso el Sabio (Madrid, 1790), p. 160; SÁnchez González de Herrero, María de las Nieves (dir.), Diccionario español de documentos alfonsíes (Madrid, Arco Libros, 2000), p. 430 y Brancaforte, Benito, Prosa histórica. Alfonso X el Sabio (Madrid, Cátedra, 1990), p. 281. Además, dentro de esta categoría de diccionarios, en Kasten, Lloyd A. y NitTi, J. J., Diccionario de la prosa castellana del Rey Alfonso X (New York, Hispanic Seminary of Medieval Studies, $2002)$, p. 1814, en la acepción de "agravio o injuria que se hace a uno", se recoge precisamente un ejemplo de un adulterio uxorio de la General Estoria, vinculado con el término tuerto. Por otra parte, en SÁNCHez GonzÁlez de Herrero, María de las Nieves (dir.), cit. (n. 67), p. 430, se vincula a la segunda acepción recogida del término tuerto, de "trampa o engaño", un caso de adulterio uxorio que estamos analizando en el presente artículo, puesto que se trata justamente del contemplado en el fuero de Puebla de Sanabria.

${ }^{68}$ Véase esta acepción del término en F.Juzgo 3,6,1, Partidas 3,14,12 y 7,17,14. Por otra parte, la asociación de dicho término con el adulterio, respecto de las obras atribuidas a Alfonso X, también se hace evidente en la General Estoria, como se comprueba en GE. 1,2: 588 y GE. 2,1: 212-213 y 281.

${ }^{69}$ Cfr. Martínez Marina, Francisco, Ensayo histórico-crítico sobre la antigua legislación de León y Castilla (Madrid, Imprenta de la Hija de D. Joaquín Ibarra, 1808), p. 170.

${ }^{70}$ Cfr. Arrazola, Lorenzo et alii, Enciclopedia española de derecho y administración o Nuevo teatro universal, (Madrid, Imprenta de los señores Andrés y Díaz, 1849), II, p. 116.

${ }^{71}$ Cfr. Partidas 4,2,8. 
forma excepcional ${ }^{72}$, mientras que no era contemplada en las Partidas $^{73}$, y es en este contexto en el que hemos de interpretar la norma que puede movernos a la duda, junto con lo dispuesto anteriormente en el propio fuero de Puebla de Sanabria de forma genérica sobre la prisión preventiva, y que ciertamente respondía a la lógica de considerar esta medida, principalmente, para las acusaciones de derecho penal, que llevasen aparejadas pena en el cuerpo. En segundo lugar, que el fuero de Puebla de Sanabria no regulase la pena por el delito no suponía una práctica inusual en el derecho la época y podía responder a dos motivos, bien a que se considerase la aplicación supletoria de otro derecho sobre este particular ${ }^{74}$, o bien a que se dejase un amplio margen al arbitrio judicial para resolver el caso en concreto ${ }^{75}$. Téngase en cuenta que, precisamente en un delito de omisión íntimamente relacionado, como es la no acusación del marido a su mujer adúltera reincidente, regulado en la ley II, del título XVII, de la Séptima Partida, Alfonso $\mathrm{X}$ no fijó pena alguna por el ilícito y dejó al juez que en cada causa resolviese en atención a las circunstancias ${ }^{76}$.

En cuanto a la preocupación del legislador por el hecho de que la mujer cometiera adulterio estando su marido fuera de la tierra, hemos de hacer notar que ésta se trataba de una preocupación recurrente en otra familia de fueros del reino de Castilla. Concretamente nos referimos a la familia de Toledo, donde podemos leer la siguiente obligación conferida a los maridos que abandonasen la villa sin la compañía de su mujer: "Et quicumque cum uxore sua ad suas hereditates ultra serram ire voluerit, relinquat caballero in domo sua, et vadat in Octobrio et veniat in primo Maio; quod si ad hunc terminum non venerit et veridicam excusationem non

72 Cfr. Tomás y Valiente, Francisco, La prisión por deudas en los Derechos castellano y aragonés, en Anuario de Historia del Derecho Español, 30 (1960), pp. 356-357.

${ }^{73}$ Cfr. ídem, pp. 368-369

${ }^{74}$ En particular, para esta familia de fueros se ha considerado al Liber Iudiciorum como su derecho supletorio por RodríGUez FERnÁndez, Justiniano, cit. (n. 66), p. 89.

75 Respecto de la figura del arbitrio judicial en este período histórico y del amplio margen para la interpretación del juzgador, cfr. SERra Ruiz, Rafael, Finalidad de la pena en la Legislación de Partidas, en Anales de la Universidad de Murcia, 21 (1962-1963), 3-4, pp. 254-255; SÁnCHeZ-Arcilla Bernal, José, El arbitrio judicial en el Antiguo Régimen. España e Indias, siglos XVI-XVIII (Madrid, Dykinson, 2013); ORTEGO GIL, Pedro, Notas sobre el arbitrio judicial usque ad mortem en el Antiguo Régimen, en Cuadernos de historia del derecho, Ext. 1 (2004), pp. 211 ss.; GonzÁlez Alonso, Benjamín, Jueces, justicia, arbitrio judicial (algunas reflexiones sobre la posición de los jueces ante el Derecho en la Castilla moderna), en Vivir el Siglo de Oro: poder, cultura e historia en la época moderna (Salamanca, Universidad de Salamanca, 2003), pp. 224 ss. y MASFERRER, Aniceto, La dimensión ejemplarizante del derecho penal municipal catalán en el marco de la tradición europea: Algunas reflexiones iushistórico-penales de carácter metodológico, en Anuario de historia del derecho español, 71 (2001), pp. 439-473.

${ }^{76}$ La punibilidad de este ilícito era defendida por Gregorio López con una pena extraordinaria, como puede comprobarse en López, Gregorio, Las Siete Partidas del Sabio Rey don Alonso el nono nueuamente glosadas por el licenciado Gregorio López (Salamanca, Imp. De Domingo de Portonariis, 1576), glosa $A$ su muger a Part 7,22,2. Para un estudio sobre el arbitrio judicial y las llamadas penas extraordinarias en el Antiguo Régimen, véase la bibliografía citada en la nota previa. 
habuerit, solvat Regis exaginta solidos. Si yero uxorem non levaverit, non relinquat cum ea caballerum; tamen ad hoc placitum veniat"77.

En todo caso, ésta se trataba de una regulación preventiva respecto del delito de adulterio, mientras que la de Puebla de Sanabria regulaba la situación una vez cometido el mismo, aprovechando la ausencia del marido, e incorporaba la exigencia de que la mujer fuere recabdada por su adulterio, al menos hasta que retornare su marido ${ }^{78}$. Pero, más allá de estas normas, esta preocupación no quedaba reflejada exclusivamente en los textos jurídicos, sino que, especialmente, la cuentística sapiencial de la época avisaba a los hombres de los riesgos de dejar a sus mujeres solas en la casa y frecuentemente recogía ejemplos de maridos deshonrados por sus mujeres al abandonar la casa o el territorio, como podemos comprobar en Disciplina Clericalis ${ }^{79}$ y en Calila e Dimna ${ }^{80}$ lo cual nos aporta datos de interés para comprender el contexto cultural determinado, cuando fueron redactadas estas leyes que centran nuestra atención, y que hemos de poner en conexión con la literatura de la General Estoria alfonsí. ${ }^{81}$

Por otra parte, respecto de la obra de los trovadores, concretamente del poeta Roi Páez de Ribela, podemos aportar una pieza de escarnio y maldecir perteneciente al nutrido repertorio constituido por las cantigas galaico-portuguesas de la época. Nos fijamos en ella, expresamente, dado que apreciamos la mofa hecha sobre un marido a causa del adulterio que sufrió en su ausencia. Esta cantiga conecta con lo que hemos visto previamente respecto de la familia foral de Toledo, ya que el ofendido dejó a su mujer en compañía y bajo la protección de un comendador, en tanto que él se no se encontrara en la villa. Aprovechando esta ausencia, fue perpetrado el delito, cuya narración se pone en boca del propio marido, bajo el irónico agradecimiento al comendador, por los cuidados ofrecidos a su mujer:

\section{Comendador, u m'eu quitei de vós e vos encomendei a mia moler, per quant' eu sei}

77 Cfr. F.Toledo 12. Véase esta norma replicada con escasas modificaciones, dentro de la misma familia foral, en F.Lorca, F.Alicante, F.Écija, F.Carmona 10 y F.Córdoba 12 y 13. Sobre este particular, cfr. CÓRDOBA DE LA LLAVE, Ricardo, Adulterio, sexo y violencia en la Castilla medieval, en Espacio, Tiempo y Forma, Serie IV, 7 (1994), p. 163; Las relaciones extraconyugales en la sociedad castellana medieval, en Anuario de estudios medievales, 16 (1986), p. 585, y Violencia y adulterio en la Andalucía bajomedieval, en La sociedad medieval andaluza, grupos no privilegiados. Actas del III Coloquio de Historia Medieval Andaluza (Jaén, Diputación Provincial de Jaén, 1984), p. 268 y Fernández-Viagas Escudero, Plácido, cit. (n. 23), p. 66.

${ }^{78}$ A este respecto, sobre el lugar donde la autoridad había de tener recabdada a la mujer, encontramos en las Partidas una norma interesante. Téngase en cuenta que el código alfonsí establecía la necesidad de tener presa a toda mujer recabdada en un monasterio, si existía en la villa, y siempre que fuera acusada de un delito que llevase aparejada pena corporal, cfr. Partidas 7,29,5.

${ }^{79}$ Cfr. Disciplina 9, 10, 11 y 13.

${ }^{80}$ Cfr. Calila pp. 139-140 y 334-335.

${ }^{81}$ Particularmente interesante es el caso recogido de la literatura clásica en GE. 2,1: 157, sobre las mujeres de los soldados del rey Vozeses, que enviaron la amenaza a sus maridos de convivir con otros hombres que las mantuviesen y amparasen, si no se tornaban a sus casas de la guerra en tierras extrañas. 
que lhi vós fezestes d'amor tenhades vós, comendador, comendad'o Demo maior.

Ca muito a fostes servir
non vo-lo poss' eu gracir;
mais, poi-la vós fostes comprar
de quant' ela ouve sabor,
tenhades vós, comendador,
comendad'o Demo maior.

E dizer-vos quer' u aren:
ela por servida se ten
de vos; e, pois que vos quer ben
como quer a min ou melhor,
tenhades a vós, comendador,
comendad'o Demo maior ${ }^{82}$.

Para acabar con esta cuestión, también podemos apreciar en el género caballeresco, concretamente en el relato de El caballero del cisne, contenido en la obra la Gran conquista de Ultramar, la narración de una acusación de adulterio interesante a nuestros fines. En ella apreciamos cómo un rey ha de abandonar su tierra por un tiempo prolongado y, en consecuencia, dejar la compañía de su mujer, que queda encomendada a un caballero. Durante este distanciamiento conyugal se produce entonces una falsa acusación de adulterio por parte de la madre del rey, que urde una trama para conseguir la muerte de su nuera ${ }^{83}$. De esta manera, a través de distintas fuentes de este siglo XIII, podemos observar la cuestión del adulterio en ausencia del marido de la villa o del lugar bajo distintas variantes. Y podemos comprobar cómo tanto la familia foral de Toledo como el fuero de Puebla de Sanabria adoptaron medidas diferentes, bien para prevenir, o bien para afrontar la situación una vez desatada la crisis.

Finalmente, en cuanto a la autoría de esta regulación del fuero de Puebla de Sanabria, debemos atribuirla, como ya hemos avanzado y se deduce en una lectura detenida del documento, a los juristas de Alfonso X, quienes se referían a este monarca con el empleo del pronombre personal nos en la cláusula relativa al adulterio ("pero tenemos nos por razón e por derecho [...]”), por lo que no

${ }^{82}$ Cfr. CEM 412. Véase la nota 59 para encontrar otras narraciones burlescas sobre el tema del adulterio. Respecto de la obra de los trovadores, conviene también mencionar el poema de Castia Gilos, tradicionalmente atribuido al trovador Ramon Vidal de Besalú, donde se muestra en tono jocoso la preocupación del rey Alfonso porque su mujer cometiera adulterio. Para comprobar si ello ocurría, el rey anuncia su falsa salida a una guerra, y deja sola en la villa a su mujer, con tan mala suerte de que ésta reconoce el plan y se toma venganza.

${ }^{83}$ Cfr. GCU. 1,51-1,65. No obstante, y a diferencia de la anterior cantiga mencionada, las sospechas de adulterio no recayeron en este caso sobre la persona a la que fue encomendada la mujer. 
corresponde asociar dicho pronombre personal con Alfonso IX, ni corresponde a sus juristas la cláusula relativa al adulterio. Pero, además, no sólo hemos de responsabilizar a Alfonso X de esta modificación, sino que la misma, como veremos, respondía a los parámetros del derecho alfonsí en materia de adulterio y no constituía una extrapolación de un texto previo de la familia de León-Benavente, ni respondía a la lógica del Liber Iudiciorum. Y a estas conclusiones llegamos inexorablemente tras constatar diferentes indicios, pero particularmente por una cuestión central, que no debe pasar desapercibida, consistente en la posibilidad de que el marido perdonase a la adúltera por su ilícito, y no ejercitase la acción, tal y como establecía la mencionada ley del fuero. En este punto, téngase en cuenta que el perdón marital a la adúltera fue una institución no recogida expresamente en el derecho foral castellano-leonés previo a la obra jurídica de Alfonso X. De hecho, y en claro contraste con lo dispuesto en el Liber Iudiciorum ${ }^{84}$, apreciamos la transcendencia jurídico penal del perdón a la adúltera por parte de su marido tanto en el Fuero Real, que protegía a la mujer de ulteriores acusaciones tras serle concedido $^{85}$, como, sobre todo, en las Partidas, donde se permitía el perdón del marido previo al proceso, el desistimiento de la acción por parte del cónyuge durante el mismo e incluso el perdón marital a la mujer condenada y recluida en un monasterio, con las consecuencias previstas en las leyes VIII y XV, del título XVII, dentro del libro VII.

En este punto, y en una interpretación histórica, al conectar la doctrina de influjo cristiano sobre el arrepentimiento de los pecados criminales en el Setenario ${ }^{86}$ con las crecientes posibilidades otorgadas al marido para que perdonase a la adúltera desde el Fuero Real a las Partidas, pasando por el fuero de Puebla de Sanabria, podremos atisbar un progresivo interés del legislador en articular el arrepentimiento de la mujer en sus normas como base del perdón marital, aunque no se conformase expresamente esta circunstancia hasta las Partidas. Téngase en cuenta que en el Fuero Real se aludía al perdón marital a la adúltera por su pecado ${ }^{87}$, lo que nos marca una configuración jurídica de esta figura bajo la influencia del cristianismo, que se acentuó en las Partidas, donde con carácter expreso se vinculaba su regulación sobre el perdón a la mujer adúltera y sobre la consiguiente reanudación de la convivencia conyugal, en sede de derecho civil, con la opinión de la Iglesia ${ }^{88}$, y, en sede de derecho penal, se establecía la no obligación de ejercitar acción alguna contra la mujer adúltera que se alejara de sus pecados ${ }^{89}$,

${ }^{84}$ Cfr. L.Iudiciorum 3,4,13.

85 Cfr. F.Real 4,7,3.

${ }^{86}$ Véase lo dispuesto en la ley XCVIII, respecto del arrepentimiento y la enmienda de los pecados criminales.

87 Cfr. F.Real 4,7,3.

${ }^{88}$ Cfr. Partidas 4,9,2.

${ }^{89}$ A esta conclusión llegamos tras una interpretación sistemática, contemplando la negligencia contemplada en la ley II, del título XVII, de la Séptima Partida, del marido que no acusara a su mujer, a la luz de lo dispuesto en la ley II, del título IX, de la Cuarta Partida, por lo que interpretamos que sólo se produciría negligencia del sujeto activo en caso de que perdonase a la adúltera reincidente.

Más allá de la legislación, si contemplamos las fuentes religiosas de la península, conviene 
además de configurarse la pena de encierro en un monasterio para la adúltera como una pena orientada al arrepentimiento y a la enmienda ${ }^{90}$. En cuanto al fuero de Sanabria, su parquedad sobre la cuestión nos impide discernir influencia cristiana alguna de forma expresa, pero, interpretado dentro de la obra alfonsí, se nos abre la posibilidad de analizar este perdón bajo los mismos parámetros.

En este sentido, si incursionamos en la arquitectura político-simbólica y en el espíritu de las leyes alfonsíes, hemos de hacer notar que Alfonso X, como rey, se autoproclamaba vicario de Dios en su reino expresamente en las Partidas ${ }^{91} \mathrm{e}$ implícitamente en el Fuero Real ${ }^{92}$ y aspiraba, al menos a priori, a que su ley reprodujera el derecho divino ${ }^{93}$, además de concebir diversas penas y medidas de otra índole como herramientas que enderezasen el camino de los pecadores ${ }^{94}$, como tuvimos ocasión ya de apuntar en un reciente artículo para la revista Hispania $S a c r a^{95}$. En este contexto, precisamente, es en el que podemos comprender el interés del legislador, concebido como vicario divino, en el arrepentimiento de la mujer por su adulterio y en admitir la posibilidad del perdón.

A esta cuestión principal del perdón, en nuestra búsqueda de una mejor comprensión de la ley de Puebla de Sanabria dentro de la obra de Alfonso X, debemos sumar una cuestión menor, de naturaleza lingüística, que interpretamos como un marcador de autoría en este contexto. Como fue explicado, en el fuero de Puebla de Sanabria se empleaba el vocablo tuerto para referirse al daño provocado por el adulterio. Esta acepción ligada al adulterio, no la encontramos en ninguna familia de fueros peninsulares distinta a la de León-Benavente, en cambio, sí se encontraba precisamente en el derecho alfonsí de las Partidas ${ }^{96}$, lo que, unido a

tener presente cómo el Codex Calixtinus configuraba la penitencia de los adúlteros, y por tanto su arrepentimiento previo, como requisito para alcanzar la gloria eterna, cfr. Calixtinus p. 17.

90 Sobre la concepción de la pena de encierro en un monasterio de la adúltera prevista en la ley XV, del título XVII, del libro VII, cfr. Serra Ruiz, Rafael, cit. (n. 75), pp. 254-255. Para una primera aproximación a estos temas, así como para un estudio más específico del perdón a la adúltera en las Partidas, cfr. Fernández-Viagas Escudero, Plácido, El perdón marital a la adúltera recluida por su delito. Un estudio de historia cultural de la Séptima Partida, en Revista Aequitas, 9 (2017), pp. 7 ss.

${ }^{91}$ Cfr. Partidas $2,1,5$ y 2,13,26.

${ }_{92}$ Cfr. F.Real 1,2, donde se afirma que Dios puso al rey como cabeza de su pueblo, para guiar a sus súbditos, como se puso así como cabeza de los ángeles.

${ }_{93}$ Cfr. Partidas 1,1,1 y 1,1,4, F.Real 1,6,1 y Espéculo 1,1,4; 1,1,5; 1,1,6 y 1,1.11.

${ }^{94}$ Como ejemplos de penas diseñadas para la enmienda de los pecadores, cfr. Partidas 1,4,63, $7,1,10,7,17,15 \mathrm{y}$, especialmente, 7,26,2, que, en determinadas circunstancias, permitía que el arrepentimiento del pecador pusiera fin a la pena impuesta y le permitiese enderezar su conducta. A este respecto, véase también cómo se concebía la prisión de la mujer como un vehículo para su arrepentimiento no sólo en Partidas 7,17,15, sino también en Partidas 7,29,5, en este caso respecto de la prisión de la mujer detenida antes de la sentencia (además de la cuestión del arrepentimiento, en la prisión de la mujer en un monasterio entraban en juego otros elementos expresamente descritos en esta ley). Por otra parte, con un carácter más genérico, respecto de la pena como medida orientada al escarmiento y a la corrección de la conducta en las Partidas, cfr. Partidas 7,31,1.

${ }^{9}$ Cfr. Fernández-Viagas Escudero, Plácido, El rey en las Partidas de Alfonso X: Su vicariato divino y su caracterización bajo esquemas de sacralidad, en Hispania Sacra, 69-139 (2017), pp. 61 ss.

96 Cfr. nota 68. 
lo anteriormente explicado y al hecho de que la regulación sobre el adulterio no se hallase contemplada en el fuero hermano de Villafranca del Bierzo, nos lleva a confirmar que esta regulación analizada del fuero de Puebla de Sanabria fue ciertamente una modificación incorporada por Alfonso X en el año 1263, cuando confirmó el hoy desconocido fuero otorgado por Alfonso IX en 1220 y lo tradujo al romance, a través de juristas que seguían unas mismas fórmulas y unos mismos parámetros en diferentes textos.

Pero, además, tenemos un último elemento que añadir a la reflexión en este presente artículo, que consiste en el alejamiento respecto de lo expresamente dispuesto en el Liber Iudiciorum, fuente principal del derecho de la familia de fueros de León-Benavente ${ }^{97}$, de lo establecido sobre el perdón marital a la adúltera en el fuero de Puebla de Sanabria. Así, mientras que en el Liber el perdón del marido no impedía acusaciones de terceros ${ }^{98}$, en el fuero de Puebla de Sanabria, por el contrario, este perdón impedía toda acusación a la adúltera. Y este alejamiento del derecho visigótico y acercamiento de lo dispuesto en el derecho alfonsí no podría, en ningún caso, ser obviado por el jurista.

\section{CONCLUSIONES}

En el presente trabajo hemos abordado varias cuestiones que merecen ser objeto de una reflexión final. En primer lugar, hemos podido comprobar cómo la legislación en materia de adulterio de los fueros de Parga y Llanes bebía principalmente del derecho justinianeo. Es por ello que tales fueros constituyen el primer referente conocido y conservado del territorio de Castilla y de León en recibir esta influencia en la regulación de este delito, varias décadas antes de la regulación alfonsí, lo que arroja luz en la importante tarea de determinar las diferentes vías de penetración del derecho común en la península. Pero, por otra parte, también hemos analizado su vinculación con el derecho visigótico, así como hemos podido interpretar estos fueros en el entramado simbólico apropiado, para enriquecer el análisis y disponer de mayores puntos de referencia con los que realizar la investigación y resolver las tramas de significación, atendiendo también a las fuentes no jurídicas.

En segundo término, la conexión de la regulación del adulterio en el fuero de Puebla de Sanabria con la literatura alfonsí, nos lleva a concluir no sólo que esta cuestión fue una de las que el rey sabio introdujo al confirmar el mencionado fuero en el año 1263, sino que la misma respondía a unos parámetros que podemos hallar en distintas obras alfonsíes. En nuestro análisis, hemos interpretado esta normativa bajo las estructuras conceptuales que se aprecian tanto en el Fuero Real como, posteriormente, en las Partidas, lo que nos lleva a descubrir determinadas preocupaciones de los juristas alfonsíes en materia de adulterio. Además, hemos sugerido la necesidad de conectar el perdón a la adúltera configurado en el fuero de

\footnotetext{
${ }^{97}$ Para un estudio de esta cuestión, cfr. Rodríguez Fernández, Justiniano, cit. (n. 66).

${ }^{98}$ Cfr. L.Iudiciroum 3,4,13.
} 
Puebla de Sanabria con la recepción de la doctrina del perdón cristiano realizada en diversas obras del scriptorium alfonsí.

Finalmente, dada la aproximación interdisciplinar, hemos podido analizar la naturaleza de la pena de muerte a la mujer adúltera prevista en estas leyes Parga y Llanes bajo el enfoque de la sociología de las religiones, como una medida de separación ritual del ser impuro sobre la comunidad, necesitada de ser preservada del contacto con lo sacro, ya sea en su vertiente pura o nefasta. En nuestra tarea de historia cultural, hemos contemplado además la identidad deteriorada no sólo de la mujer delincuente, sino también del marido ofendido por el ilícito, concebido como un ser pusilánime en el entramado cultural de la época, bajo las aportaciones de destacados sociólogos y antropólogos, que nos ofrecen el marco teórico y las herramientas interpretativas adecuadas para nuestro trabajo.

La conexión de las normas previstas en estas leyes con documentos no jurídicos de la época, nos permite, por otra parte, abordar con mejores garantías determinadas instituciones sociales que aparecían en estos textos, como el honor del marido, que se nos presenta necesariamente vinculado a la fidelidad sexual de su mujer, y el perdón a la adúltera, como institución social de importantes consecuencias en materia penal.

\section{BiBLIOGRAFÍA}

Fuentes empleadas

1. Fuentes jurídicas

Anta Lorenzo, Lauro (ed.), El fuero de Sanabria, en Studia historica. Historia medieval, 5 (1987), pp. 161 ss.

Arboleda Porras, Pedro Andrés (ed.), El fuero de Sabiote, en Cuadernos de Historia del Derecho, 1 (1994), pp. 243 ss.

BriXIENsIs, Bartholome (ed.), Glossa ordinaria ad Decretum Gratiani, (Romae, 1584).

Calleja Puerta, Miguel (ed.), El fuero de Llanes, Edición crítica (Oviedo, Sueve, 2003).

Cortes de los Antiguos Reinos de Aragón y de Valencia y Principado de Cataluña (Madrid, Real Academia de la Historia, 1899).

Cots y Gorchs, Jaume (ed.), Les consuetuds d'Horta (avui Horta de Sant Joan) a la ratlla del Baix Aragó, en Estudis Universitaris Catalans, 15 (1930), pp. 304 ss.

El libro de los fueros de Castiella (Barcelona, Universidad de Barcelona, 1924).

Field, Hugh (ed.), Ramon Vidal de Besalú. Obra poética (Barcelona, Curial, 1989).

Furs de Jaume I (1238-1271) (Valencia: Generalitat Valenciana-Universitat Jaume I, 2016), disponible en http://www.jaumeprimer.uji.es/cgi-bin/fursv/ [consultado el 23/12/2016].

García de Valdeavellano, Luis (ed.), El fuero de León. Comentarios (Madrid, Hullera Vasco-Leonesa, 1983).

GarCía DEL Corral, Idelfonso L. (trad. y com.), Cuerpo de derecho civil romano (Barcelona, Jaime Molinas, 1889).

García Oliva, María Dolores (trans.), Fuero romanceado de Cáceres. Fuero original y transcripción disponibles en: http://www.ayto-caceres.es/ciudad/el-fueroromanceado-transcripcion [consultado el 2/1/2017]. 
González Palencia, Ángel y GonzÁlez Palencia, Inocenta (eds.), El fuero latino de Albarracin (Madrid, Tip. de Archivos, 1932).

Gorosh, Max (ed.), El Fuero de Teruel según los Mss. 1-4 de la Sociedad Económica Turolense de Amigos del Pais y 802 de la Biblioteca Nacional de Madrid (Estocolmo, LHMA, 1950).

Gutiérrez Cuadrado, Juan (ed.), Fuero de Úbeda (Valencia, Universidad de Valencia, 1979).

Herculano, Alexandre (ed.), Portugaliae Monumenta Historica, Leges et Consuetudines (Lisboa, Academia das Ciências de Lisboa, 1856).

Holmér, Gustaf (ed.), El fuero de Estella según el manuscrito 944 de la Biblioteca de Palacio de Madrid (Karlshamn, Johannssons Boktryckeri, 1963).

Ilaguerri, Pablo y Lapuerta, Segundo (eds.), Fuero General de Navarra (Pamplona, Diputación Provincial de Navarra, 1869).

Lindley Cintra, Luis Felipe (ed.), A linguagem dos foros de Castelo Rodrigo (Lisboa, Casa da Moeda, 1984).

López, Gregorio (ed.), Las Siete Partidas del Sabio Rey don Alonso el nono nueuamente glosadas por el licenciado Gregorio López (Salamanca, Imp. De Domingo de Portonariis, 1576).

Loscercales de Valdeavellano, Pilar (ed.), Costumbres de Lérida (Barcelona, Universidad de Barcelona, 1946).

Los códigos españoles concordados y anotados (Madrid, Imp. de la Publicidad, 1849).

LuÑo PeÑa. Enrique (ed.), Legislación foral de don Rodrigo Jiménez de Rada (Zaragoza, Universidad de Zaragoza, 1927).

Majada Neila, Jesús, (ed.), Fuero de Plasencia. Introducción, traducción y vocabulario (Plasencia, Ayuntamiento de Plasencia, 1986).

Marcos Burriel, Andrés (ed.), Memorias para la vida del santo rey Don Fernando III (Barcelona, Imp. de la viuda de don Joaquín Ibarra, 1800).

Marín Pérez, Pascial (dir.), Los fueros de Sepúlveda (Segovia, Diputación Provincial de Segovia, 1953).

Martín Lázaro, Antonio (ed.), Fuero castellano de Béjar (siglo XIII). Preliminar, transcripción y notas (Madrid, Tip. Revista de Archivos, 1926).

Martínez Díez, Gonzalo (ed.), Fueros locales en el territorio de la provincia de Burgos (Burgos, Caja de Ahorros Municipal de Burgos, 1982).

Mellado Rodríguez, Joaquín (ed.), Fuero de Córdoba, edición crítica y traducción, en Arbor, 154 (2000), pp. 191 ss.

Martínez Martínez, Faustino (ed.), Antología de textos forales del antiguo reino de Galicia (siglos XII-XIV), en Cuaderno de Historia del Derecho, 10 (2003), pp. 247 ss.

Martín de Palma, María Teresa (ed.), Los fueros de Villaescusa de Haro y Huete (Málaga, Universidad de Málaga, 1984).

MolHo, Mauricio (ed.), El fuero de Jaca. Edición crítica (Zaragoza, Escuela de Estudios Medievales, 1964).

Muñoz Romero, Tomás (ed.), Colección de fueros municipales y cartas pueblas de los reinos de Castilla, León, Corona de Aragón y Navarra (Madrid, Imprenta de Don José María Alonso, 1847).

Oliver, Bienvenido (ed.), Libre de les costums generals escrites de la insigne ciutat de Tortosa (Madrid, 1881).

Quesada Huertas, Pablo (ed.), El fuero de Andújar: Estudio y edición (Jaén, Universidad de Jaén, 2006). 
RiU, Manuel et alii (eds.), Textos comentados de época medieval (siglos V al XII) (Barcelona, Editorial Teide, 1975).

Rodríguez Pernández, Justiniano (ed.), Los fueros del reino de León (León, Ediciones Leonesas, 1981).

Roudil, Jean (ed.), El fuero de Baeza. Edición, estudio y vocabulario (La Haya, Van Goor Zonen, 1962).

-Les fueros d'Alcaraz et d'Alarcón (Paris, Faculté des Lettres et Sciences Humanes de Strasburg, 1968).

SÁez Sánchez, Emilio (ed.), El fuero de Coria (Madrid, Instituto de Estudios de Administración Local, 1949).

Sanz Fuentes, María Josefa, Aportación al estudio de la cancillería de Alfonso X, en Gades, 1 (1978), pp. 183-209.

Tilander, Gunnar (ed.), Vidal Mayor. Traducción aragonesa de la obra In Excelsis Dei Thesauris de Vidal de Canellas (Lund: LHMA, 1956).

Tejada y Ramiro, Juan (ed.), Colección de cánones y de todos los concilios de la Iglesia de España y de América (Madrid, Imprenta de D. Pedro Montero).

Torres Fontes, Juan (ed.), Fueros y privilegios de Alfonso X el Sabio al reino de Murcia (Murcia, Nogues, 1963).

Ureña y Smenjaud, Rafael (ed.), Fuero de Zorita de los Canes según el códice 217 de la Biblioteca Nacional (siglos XIII al XIV) y sus relaciones con el fuero latino de Cuenca y el romanceado de Alcázar (Madrid, Est. Tip. de Fortanet, 1911).

-Fuero de Cuenca (formas primitiva y sistemática: Texto castellano y adaptación al fuero de Iznatoraf) (Madrid, Tip. de Archivos, 1935).

Ureña y Smenjaud, Rafael y Bonilla Sanmartín, Adolfo (eds.), Fuero de Usagre (siglo XIII). Anotado con las variantes del de Cáceres) (Madrid, H. de Reus, 1907).

VAlls I TABerner, Fernando, Los usatges de Barcelona: estudios, comentarios y edición bilingües del texto (Barcelona, Promociones Publicaciones Universitarias, 1984).

2. Otras fuentes literarias

Berceo, Gonzalo, Obras completas (Madrid, Biblioteca Castro, 2003).

Bocados de oro (Toledo, 1507). Disponible en: http://books.google.es/books?id=1S zPlyIcYA8C\&pg=PT12\&lpg=PT12\&dq =bocados + de + oro\&source $=$ bl\&ots $=0$ TigOWm6Y3\&sig=aGH8a36h0zH3fyvZG5ffBU7GDo\&hl=es\&sa=X\&ei=p MJqU_TxOsKr0QWdu4Fg\&redir_esc $=\mathrm{y} \# \mathrm{v}=$ onepage $\& \mathrm{q}=$ bocados $\% 20 \mathrm{de} \% 20$ oro\&f=false [consultado el 4/3/2017].

DölHA, Hans-Jörg, (ed.), El libro de Calila e Dimna (1251) (Zurich, Universidad de Zurich, 2007).

DucaY, Esperanza (trad.), Disciplina clericalis (Zaragoza, Guara, 1980).

Estévez Sola, Juan Antonio (ed.), Crónica najerense (Madrid, Akal, 2003).

JiMÉNEZ DE RADA, Rodrigo, Historia de los hechos de España (Madrid, Alianza Editorial, 1989).

LaCARra, María Jesús (ed.), Sendebar (Madrid, Cátedra, 1989).

Mettman, Walter (ed.), Cantigas de Santa María de Alfonso Xel Sabio (Vigo, Edicións Xerais de Galicia, 1981).

Menéndez Pidal, Ramón (ed.), Primera crónica General de España (Madrid, BaillyBailliere é Hijos, 1906).

Moralejo, Abelardo (dir.), Liber Sancti Jacobi: Codex Calixtinus (Santiago de Compostela, Xunta de Galicia, 2014). 
Gayangos, Pascual (ed.), La gran conquista de Ultramar que mandó escribir el Rey Don Alfonso el Sabio (Madrid, Rivadeneyra Impresor, 1858).

Rodrigues Lapa, Manuel (ed.), Cantigas d'escarnho e de mal dizer. Ediçáo crítica (Vigo, Editorial Galaxia, 1965).

SÁnchez-Prieto Borja, Pedro (ed.), General Estoria (Madrid, Fundación José Antonio de Castro, 2009).

URía MaQUA, Isabel y GONZÁlez ÁlVAREZ, Jaime, El libro de los doce sabios y Relación de los reyes de León y Castilla. Códice ovetense (Oviedo, Universidad de Oviedo, 2002).

\section{Literatura}

Alonso, Martín, Diccionario medieval español: desde las Glosas Emilianenses y Silenses (s. X) hasta el siglo XV (Salamanca, Universidad Pontifica de Salamanca, 1986).

Arauz Mercado, Diana, Solteras, casadas y viudas. La condición jurídica de las mujeres castellano-leonesas en la normativa penal (siglos XII-XIV), en DeL VAL VALDIVIESO, María Isabel; MarTínez SoPEnA, Pascual (coords.), Castilla y el mundo feudal. Homenaje al profesor Julio Valdeón (Valladolid, Junta de Castilla y León-Universidad de Valladolid, 2009), pp. 323 ss.

Arranz GuZmán, Ana, Imágenes de la mujer en la legislación conciliar, en Las mujeres medievales y su ámbito jurídico (Madrid, Universidad Autónoma de Madrid, 1983), pp. 33 ss.

Arrazola, Lorenzo et alii, Enciclopedia española de derecho y administración o Nuevo teatro universal, (Madrid, Imprenta de los señores Andrés y Díaz, 1849).

Aznar Gil, Federico Rafael, La institución matrimonial en la Hispania cristiana bajomedieval (1215-1563) (Salamanca, Universidad de Salamanca, 1989).

Barrero García, Ana María, La familia de los Fueros de Cuenca, en Anuario de Historia del Derecho Español, 46 (1976), pp. 713 ss.

Barrero García, Ana María; Alonso Martín, María Luz, Textos de derecho local español en la Edad Media: catálogo de fueros y costums municipales (Madrid, CSIC, 1989).

Bermejo Castrillo, Miguel Ángel, Parentesco, matrimonio, propiedad y herencia en la Castilla altomedieval (Madrid, Universidad Carlos III de Madrid, 1996).

Brancaforte, Benito, Prosa histórica. Alfonso X el Sabio (Madrid, Cátedra, 1990).

Brundage, James A., Adultery and Fornication: A Study in Legal Theology, en Bullough, Vern L.; Brundage, Jamen (eds.), Sexual Practices \& the Medieval Church (New York, Prometheus Books, 1994), pp. 129 ss.

BRUNDAGE, James A., La ley, el sexo y la sociedad cristiana en al Europa medieval (México D.F., Fondo de cultura económica, 2000).

CABANes Jiménez, Pilar, El deseo femenino a la luz de algunas composiciones literarias medievales, en Lemir, 9 (2005).

CAILlois, Roger, El hombre y lo sagrado (1939, reimp. México D.F., Fondo de Cultura Económica, 1984).

Cantarella, Eva, Según Natura: la bisexualidad en el mundo antiguo (Madrid, Akal, 1991).

CARLÉ, María del Carmen, Apuntes sobre el matrimonio en la Edad Media española, en Cuadernos de historia de España, 63-64 (1980), pp. 115 ss.

Castillo Lluch, Mónica, De verbo vedado: consideraciones lingüisticas, en Cahiers de linguistique et de civilisation hispaniques médiévales, 27 (2004), pp. 23 ss.

Collantes de Terán de la Hera, M. J., El delito de adulterio en el derecho general de Castilla, en Anuario de historia del derecho español, 66 (1996), pp. 201 ss. 
Clavero, Bartolomé, Historia del Derecho: Derecho común (Salamanca, Universidad de Salamanca, 2008).

Cejador y Frauca, Julio, Vocabulario medieval castellano (Madrid, Visor Libros, 1990).

Córdoba de la Llave, Ricardo, Violencia y adulterio en la Andalucía bajomedieval, en La sociedad medieval andaluza, grupos no privilegiados. Actas del III Coloquio de Historia Medieval Andaluza (Jaén, Diputación Provincial de Jaén, 1984).

- Las relaciones extraconyugales en la sociedad castellana medieval, en Anuario de estudios medievales, 16 (1986).

-Adulterio, sexo y violencia en la Castilla medieval, en Espacio, Tiempo y Forma, Serie $I V, 7$ (1994), pp. 153 ss.

Dillard, Heath, La mujer en la Reconquista (Madrid, Editorial Nerea, 1993).

DurKHeIm, Émile, Las formas elementales de la vida religiosa, (Buenos Aires, Schapire, 1968).

Eliade, Mircea, Lo sagrado y lo profano, (4a edición, Barcelona, Paidós, 2014).

Fernández Regatillo, Eduardo, El Derecho matrimonial en las Partidas y en las Decretales, en Acta Congressus Iuridici Internationalis, Pontificium Institutum Utriusque Iuris (Roma, 1936), III, pp. 297 ss.

FERnÁndeZ-Viagas Escudero, Plácido, La honra del marido como bien jurídico protegido en el delito de adulterio: Un estudio de las Partidas a la luz de sus antecedentes normativos y de su contexto jurídico, en Clío \& Crimen, 13 (2016), pp. 53 ss.

- El perdón marital a la adúltera recluida por su delito. Un estudio de historia cultural de la Séptima Partida, en Revista Aequitas, 9 (2017), pp. 7 ss.

- El rey en las Partidas de Alfonso X: Su vicariato divino y su caracterización bajo esquemas de sacralidad, en Hispania Sacra, 69-139 (2017), pp. 61 ss.

GaCto Fernández, Enrique, La filiación ilegitima en la historia del Derecho español, en Anuario de Historia del Derecho Español, 41 (1971), pp. 907 ss.

García-Gallo de Diego, Alfonso, El Fuero de León. Su historia, textos y redacciones, en Anuario de Historia del Derecho Español, 39 (1969), pp. 5 ss.

-Los fueros de Benavente, en Anuario de Historia del Derecho Español, 41 (1971), pp. 1143 ss.

García García, Antonio, Derecho común en España. Los juristas y su obra (Murcia, Universidad de Murcia, 1991).

-Derecho común en Castilla durante el siglo XIII, en Glossae: European Journal of Legal History, 5-6 (1993-1994), pp. 45 ss.

García de VAldeavellano, Luis, El apellido. Notas sobre el procedimiento in-fraganti en el derecho español medieval, en Cuadernos de Historia de España, 7 (1947), pp. 67 ss.

GARCía SÁnCHEZ, Justo, Los derechos reales romanos en el fuero de Cuenca, en Glossae: European Journal of Legal History, 8 (1996), pp. 53 ss.

Gauvard, Claude, La fama, une parole fondatrice, en Médiévales, 12-24 (1993), pp. 5 ss. GeERTZ, Clifford, La interpretación de las culturas (1973, Gedisa, reimp. Barcelona, 2003).

GIRARD, René, La violencia y lo sagrado (1972, reimp. Barcelona, Anagrama, 1983).

GofFMAn, Erving, Estigma: La identidad deteriorada (1963, reimp. Buenos AiresMadrid, Amorrortu, 2006).

GonZÁlez Alonso, Benjamín, Jueces, justicia, arbitrio judicial (algunas reflexiones sobre la posición de los jueces ante el Derecho en la Castilla moderna), en Vivir el Siglo de Oro: poder, cultura e historia en la época moderna (Salamanca, Universidad de Salamanca, 2003), pp. 224 ss. 
GonZÁlez JimÉnez, Manuel, Sobre fueros, concejos y politica municipal de Alfonso X, en II Congreso de Historia de Albacete: del 22 al 25 de noviembre de 2000 (Albacete, Instituto de Estudios Albacetenses “Don Juan Manuel”, 2002), pp. 11 ss.

Gortázar Rotaeche, Cristina, J., Derecho de asilo y no rechazo del refugiado (Madrid, Dykinson, 1997)

Kasten, Lloyd A.; NitTi, J. J., Diccionario de la prosa castellana del Rey Alfonso X (New York, Hispanic Seminary of Medieval Studies, 2002).

LeEuw, Gerardus van der, La fenomenología de la religión (México-Buenos Aires, Fondo de Cultura Económica, 1964).

Lugue Talaván, Miguel, La inmunidad del sagrado o el derecho de asilo eclesiástico a la luz de la legislación canónica y civil indiana, en Martínez López Cano, María del Pilar; Cervantes Bello, Francisco Javier (coords.), Los concilios provinciales en la Nueva España. Reflexiones e influencias (México D. F., Universidad Autónoma de México-Benemérita Universidad Autónoma de Puebla, 1995), pp. 253 ss.

MADERO, Marta, Manos violentas, palabras vedadas: la injuria en Castilla y León (siglos XIII-XV) (Madrid, Taurus, 1992).

MarTínez Marina, Francisco, Ensayo histórico-crítico sobre la antigua legislación de León $y$ Castilla (Madrid, Imprenta de la Hija de D. Joaquín Ibarra, 1808).

MASFERRER, Aniceto, La dimensión ejemplarizante del derecho penal municipal catalán en el marco de la tradición europea: Algunas reflexiones iushistórico-penales de carácter metodológico, en Anuario de historia del derecho español, 71 (2001), pp. 439-473.

Mendoza Garrido, Juan Miguel, Delincuencia y represión en la Castilla bajomedieval (Grupo Editorial Universitario, 1999).

Montero Cartelle, Enrique, La sexualidad medieval en sus manifestaciones lingüisticas: pecado, delito y algo más, en Clío \& Crimen, 7 (2010), pp. 49 ss.

Ortego Gil, Pedro, Notas sobre el arbitrio judicial usque ad mortem en el Antiguo Régimen, en Cuadernos de historia del derecho, Ext. 1 (2004), pp. 211 ss.

Osaba, Esperanza, El adulterio uxorio en la Lex Visigothorum (Madrid, Marcial Pons, 1997).

Отто, Rudolf, Lo santo. Lo racionaly lo irracional en la idea de Dios (Madrid, Revista de Occidente, 1965).

Pérez Martín, Antonio, El derecho común y el fuero de Cuenca, en Glossae: European Journal of Legal History, 8 (1996), pp. 77 ss.

- El estudio de la recepción del derecho común en España, en SAlVAdor CODERCH, Pablo; CERDÁ RUíz-FuES, Joaquím (coords.), I Seminario de historia del derecho y derecho privado: nuevas técnicas de investigación (Barcelona, Universitat Autònoma de Barcelona, 1985), pp. 241 ss.

-Los fueros extensos y el derecho común, en Anales de Derecho, 15 (1997), pp. 75 ss.

Pérez Mozún, Diego, Diccionario alfabético y ortográfico de las voces que en sus célebres Partidas usó el rey don Alfonso el Sabio (Madrid, 1790).

PITT-Rivers, Julian, La enfermedad del honor, en Anuario IEHS: Instituto de Estudios histórico sociales, 14 (1999), pp. 235 ss.

Rodríguez Gallardo, Francisco, El ius puniendi en delitos de adulterio (análisis histórico-jurídico), en Revista de Derecho Penaly Criminología, 5 (1995), pp. 881 ss.

Rodríguez Ortiz, Victoria, Historia de la violación. Su regulación jurídica hasta fines de la Edad Media (Madrid, Consejería de Educación y Cultura, 1997).

ROLDÁN VERDEjo, Roberto, Los delitos contra la vida en los fueros de Castilla y León (La Laguna, Universidad de La Laguna, 1978). 
RuCQuor, Adeline, Aimer das l'Espagne Médiévale. Plaisirs licites et illicites (Les Belles Lettres, 2008).

Ruiz de la PeÑa Solar, Juan Ignacio, La condición de la mujer a través de los ordenamientos jurídicos de la Asturias medieval (siglos XII al XIV), en Las mujeres en las ciudades medievales (Madrid, 1984), pp. 59 ss.

Sánchez González de Herrero, María de las Nieves (dir.), Diccionario español de documentos alfonsies (Madrid, Arco Libros, 2000).

Sánchez-Arcilla Bernal, José, El arbitrio judicial en el Antiguo Régimen. España e Indias, siglos XVI-XVIII (Madrid, Dykinson, 2013).

Sancristóbal IbÁÑez, Miguel Ángel, El matrimonio en Portugal durante la baja Edad Media, en Edad Media: revista de historia, 5 (2002), pp. 161 ss.

Santomá Juncadella, Luis, El milagro de la mujer lapidada. Crítica literaria de la versión en occitano cispirenaico aragonés, en Revista de Filología Románica, 27 (2010), pp. 285 ss.

SAnZ GonZÁlez, Mariano, Derecho de asilo: ¿Misericordia o justicia?, en Revista española de derecho canónico, 51-137 (1994), pp. 477 ss.

Serra Ruiz, Rafael, Finalidad de la pena en la Legislación de Partidas, en Anales de la Universidad de Murcia, 21 (1962-1963), 3-4, pp. 200 ss.

-Honor, honra e injuria en el derecho medieval español (Murcia, Sucesores de Nogués, 1969).

Tomás y Valiente, Francisco, La prisión por deudas en los Derechos castellano y aragonés, en Anuario de Historia del Derecho Español, 30 (1960), pp. 249 ss.

Valladolid, Antonio, Disertacion del origen del asylo, e inmunidad de los Templos (Madrid, 1773).

Widengren, Geo, Fenomenología de la religión (1945, reimp. Madrid, Ediciones Cristiandad, 1976). 